\title{
Motivation and Affective Judgments Differentially Recruit Neurons in the Primate Dorsolateral Prefrontal and Anterior Cingulate Cortex
}

\author{
-Ken-ichi Amemori, Satoko Amemori, and Ann M. Graybiel \\ McGovern Institute for Brain Research and Department of Brain and Cognitive Sciences, Massachusetts Institute of Technology, Cambridge, Massachusetts \\ 02139
}

\begin{abstract}
The judgment of whether to accept or to reject an offer is determined by positive and negative affect related to the offer, but affect also induces motivational responses. Rewarding and aversive cues influence the firing rates of many neurons in primate prefrontal and cingulate neocortical regions, but it still is unclear whether neurons in these regions are related to affective judgment or to motivation. To address this issue, we recorded simultaneously the neuronal spike activities of single units in the dorsolateral prefrontal cortex (dlPFC) and the anterior cingulate cortex (ACC) of macaque monkeys as they performed approach-avoidance (Ap-Av) and approach-approach (Ap-Ap) decision-making tasks that can behaviorally dissociate affective judgment and motivation. Notably, neurons having activity correlated with motivational condition could be distinguished from neurons having activity related to affective judgment, especially in the Ap-Av task. Although many neurons in both regions exhibited similar, selective patterns of task-related activity, we found a larger proportion of neurons activated in low motivational conditions in the dIPFC than in the ACC, and the onset of this activity was significantly earlier in the dIPFC than in the ACC. Furthermore, the temporal onsets of affective judgment represented by neuronal activities were significantly slower in the low motivational conditions than in the other conditions. These findings suggest that motivation and affective judgment both recruit dIPFC and ACC neurons but with differential degrees of involvement and timing.
\end{abstract}

Key words: anterior cingulate cortex; decision making; macaque; prefrontal cortex; primate

\section{Introduction}

Approach-avoidance (Ap-Av) conflict arises when an individual must decide between acceptance and rejection of a prospective offer having a mixture of positive and negative attributes (Miller, 1971; Vogel et al., 1971). These judgments are determined by cost-benefit integration of positive and negative values related to each component of the combined offer (Talmi et al., 2009; Amemori and Graybiel, 2012) but concurrently induce motivational responses that affect dynamic aspects of the decisionmaking process (Tversky and Shafir, 1992; Diederich, 2003). For instance, macaque monkeys tend to slow down task performance or sometimes defer performance when the positive aspects of the offer are frustratingly low (Hassani et al., 2001; Watanabe et al.,

\footnotetext{
Received April 29, 2014; revised Dec. 2, 2014; accepted Dec. 11, 2014.

Author contributions: K.A. and A.M.G. designed research; K.A., S.A., and A.M.G. performed research; K.A., S.A., and A.M.G. analyzed data; K.A. and A.M.G. wrote the paper.

This work was supported by National Institutes of Health Grant R01 NS025529, Office of Naval Research Grant N00014-07-1-0903, CHDI Foundation Grant A-5552, the Simons Center for the Social Brain, and the National Parkinson Foundation (Lynn Diamond Fellowship). We thank Margo Cantor for her skillful assistance in training monkeys and surgical procedures, Drs. Simon Hong, Hideki Shimazu, and Patrick Tierney for their insightful comments and suggestions, Dr. Daniel Gibson for his help with data analysis, Alex McWhinnie for editing figures, and Dr. Yasuo Kubota for help preparing this manuscript.

The authors declare no competing financial interests.

Correspondence should be addressed to Ann M. Graybiel, 43 Vassar Street, Building 46-6133, Cambridge, MA 02139. E-mail: graybiel@mit.edu.

DOI:10.1523/JNEUROSCI.1731-14.2015

Copyright $\odot 2015$ the authors $\quad 0270-6474 / 15 / 351939-15 \$ 15.00 / 0$
}

2001; Isoda and Hikosaka, 2008) and when the negative aspects are not threatening (Kobayashi et al., 2006). Importantly, such motivational responses are considered to be dissociable from judgments based on affect (Lang et al., 1998; Roesch and Olson, 2004). Highly threatening, aversive offers reduce the utility value of acceptance but also are thought to activate an avoidance motivation to facilitate performance (Bradley et al., 2001, 2008). Here we used a conflict decision-making paradigm that can behaviorally dissociate affective judgment of likes and dislikes from motivational factors that control the dynamic aspects of decision-making. We used this potential in an attempt to dissociate components of value-based decision-making by examining the neuronal correlates of affective judgment and motivation.

Both the dorsolateral prefrontal cortex (dlPFC) and the anterior cingulate cortex (ACC) have been implicated in such costbenefit integration in nonhuman primates (Kennerley et al., 2006, 2011; Hosokawa et al., 2013) and humans (Knoch et al., 2006; Talmi et al., 2009), and these regions are known to be critical for goal-directed behavior (Matsumoto et al., 2003) and value-based decision-making (Barraclough et al., 2004; Seo and Lee, 2007). Activity in the dlPFC is enhanced especially in response to motivationally intriguing goals (Watanabe, 1996; Amemori and Sawaguchi, 2006; Kennerley and Wallis, 2009). Focal microstimulation of part of the pregenual ACC induces negative bias in such value-based decision-making (Amemori and Graybiel, 2012), causally demonstrating an involvement of 
part of the ACC in subjective evaluation (Padoa-Schioppa, 2011; Cai and Padoa-Schioppa, 2012). However, it has not been clear whether the dlPFC and the ACC have distinct functions in the affective judgment and motivational regulation that influence neural processing as decision-making evolves over time. Using the Ap-Av decision-making paradigm, we tested whether the dlPFC and ACC of macaque monkeys, two cortical regions that have been implicated in affective processing and motivation, have dissociable activity patterns related to these functions by recording with chronic multielectrode methods (Feingold et al., 2012).

\section{Materials and Methods}

Subjects and experimental conditions. Two female Macaca mulatta monkeys (monkey A, $6.8 \mathrm{~kg}$; monkey S, $7.5 \mathrm{~kg}$ ) were studied in experiments following procedures approved by the Committee on Animal Care of the Massachusetts Institute of Technology. Before training, the monkeys were habituated to sitting in a monkey chair, and sterile surgery was performed with anesthesia induced by intramuscularly administered atropine $(0.05 \mathrm{mg} / \mathrm{kg})$ and ketamine $(10 \mathrm{mg} / \mathrm{kg})$, followed by inhalation of $1-2.5 \%$ sevoflurane with $2 \mathrm{~L}$ of $\mathrm{O}_{2}$, to implant over the occipital bone a titanium head post, secured by titanium screws and bone cement. For all surgeries, the monkeys were maintained on analgesics postoperatively, and prophylactic antibiotics were injected on the day of surgery and daily thereafter for 1 week.

Task procedures. The two female monkeys were trained to perform Ap-Av and approach-approach (Ap-Ap) tasks (Amemori and Graybiel, 2012). In the Ap-Av task (Fig. 1A), a white central fixation spot and a gray rectangular frame simultaneously appeared on a screen. When the monkey placed its hand on a designated start position in front of a joystick, an infrared photobeam sensor detected the placement, inducing the rectangular frame to turn white. The monkey was required to hold its hand in the start position for $1.5 \mathrm{~s}$ (fixation period). If the monkey released its hand from the start position, the rectangular frame became gray, requiring the monkey to begin again with fixation. After the fixation period, a compound visual cue, consisting of red and yellow horizontal bars, appeared on the screen. The length of the red bar corresponded to the offered amount of liquefied food, which ranged from 0.1 to $2.0 \mathrm{ml}$. The length of the yellow bar corresponded to the offered pressure of the airpuff, which ranged from 0 to 50 psi. These two offered outcomes were delivered only when the monkey made an approach decision. The length of the bars could be varied over 101 steps, independently and pseudorandomly. The cues remained on for $1.5 \mathrm{~s}$ (cue period), and the monkey had to maintain start-position contact during this period. If the monkey released the contact (a commission error), the trial was terminated, and an airpuff corresponding to that indicated by the length of the yellow bar was delivered to the monkey's face, accompanied by a sound signaling error. If the monkey continued the trial, then after the cue period, two target cues (a white cross and a white square) appeared above and below the cue. At the same time, a cursor (white circle) whose vertical location could be controlled by the joystick appeared at the center of the screen. The monkey was required to report its decision by using a joystick to move the cursor toward one of the two targets within $3 \mathrm{~s}$ (response period). The locations of the targets were alternated randomly. If the monkey did not respond within the allotted $3 \mathrm{~s}$ response period, the trial was counted as an omission error, and an airpuff as indicated by the yellow bar was delivered, accompanied by the error sound. When the monkey chose the square target, a sound signaling avoidance was played, and $500 \mathrm{~ms}$ later, the minimum and constant amount of reward (liquefied food, $0.1 \mathrm{ml}$; equivalent to the minimum offer by the red bar) was delivered to maintain the monkey's motivation to continue the task. If the monkey chose the cross target, a sound signaling approach was played, and $500 \mathrm{~ms}$ later, an airpuff whose pressure was indicated by the yellow bar was delivered to the monkey's face for $800 \mathrm{~ms}$. Liquefied food, in an amount signaled by the red bar, was then delivered $1 \mathrm{~s}$ later for $1.5 \mathrm{~s}$. After each trial, a $5 \mathrm{~s}$ intertrial interval occurred. The amount of reward and the pressure of airpuff were controlled by a computer-controlled pump (L/S Masterflex; Cole-Parmer) and a transducer (900-EIA; Control Air).

The monkeys were also trained to perform an Ap-Ap task (Fig. 1F; Amemori and Graybiel, 2012). The task design and procedural details for this task were the same as those in the Ap-Av task, except that the outcomes of the decisions were always rewards. When the monkey chose the square target, a sound signaling approach occurred, and $500 \mathrm{~ms}$ later, the liquid food reward was delivered for $1.5 \mathrm{~s}$ at an amount indicated by the length of the yellow bar. When the monkey chose the cross target, a sound signaling approach was triggered, and $500 \mathrm{~ms}$ later, reward was delivered for $1.5 \mathrm{~s}$ at an amount indicated by the length of the red bar. The amount of reward per unit length of the red bar was twice that of the yellow bar, so that the association between cue and target was comparable for the Ap-Av and Ap-Ap tasks. When commission or omission errors occurred, the trial was terminated without reward delivery.

Neuronal recording. After behavioral training, in a second sterile surgery, a plastic $40 \times 40 \mathrm{~mm}$ recording chamber was implanted on the skull and secured by bone cement and ceramic screws at coordinates stereotaxically determined for each monkey. The chamber contained a plastic grid with openings spaced at $1 \mathrm{~mm}$ intervals to serve as guides allowing parallel microelectrode penetrations. After the chamber implantation, magnetic resonance images (T2-weighted turbo spin echo, $300 \mu \mathrm{m}$ in resolution, $1 \mathrm{~mm}$ slice thickness) were taken to allow subsequent identification of the electrode tracks. Then, with surgical anesthesia and sterile conditions, the skull overlying the targeted regions was removed. After recovery, sets of platinum-iridium electrodes (impedance, 0.8-1.5 M $\Omega$; FHC) were gradually lowered into the neocortex (Feingold et al., 2012). All electrodes were held by custom-made micromanipulators affixed to the grid. For the first implant in monkey A, 36 electrodes were implanted simultaneously into the neocortical targets (24 in the dlPFC and 12 in the ACC), and 18 additional electrodes were implanted into the striatum for another experimental purpose. For the second implant in monkey A, 32 electrodes were implanted in the neocortex (18 in the dIPFC and 24 in the ACC). For the first implant in monkey S, 12 electrodes were implanted into the ACC. For the second implant in monkey S, 30 electrodes were implanted into the neocortex (12 in the dlPFC and 18 in the ACC), and 15 additional electrodes were implanted into the striatum.

The recording and task control system consisted of five networked computers and other peripheral equipment. Eye positions were monitored by an infrared eye-movement camera system (Eyelink CL; SR Research). Two computers controlled the task based on a CORTEX system developed by the National Institute of Mental Health. For recording, a digital data acquisition system (Digital Lynx; Neuralynx) collected all signals and task event markers. Signals from the microelectrodes were amplified and stored by the Digital Lynx system. Data were later classified into single-unit activities using Offline Sorter (Plexon) and were analyzed using MATLAB (Mathworks). Recordings were made while the monkeys performed each of the two (Ap-Av and Ap-Ap) tasks in alternating blocks of 150 trials (Fig. $1 K$ ). Between blocks, we inserted a $10 \mathrm{~s}$ interblock interval, during which a white spot appeared at the center of the screen as an explicit signal of the block change.

Econometrics models deriving chosen value and entropy. To approximate parametrically the monkey's choice behavior, we used an econometrics model. We adopted the conditional logit model (McFadden, 1974; Train, 2003). With the monkeys' decision sampled in each session (Fig. 2A), we reversely inferred these subjective values as follows. If there are two options associated with the cross and square targets, the probability of choosing the cross target can be written as $p_{+}=1 /(1+$ $\left.\exp \left(-\left(U_{+}-U_{\square}\right)\right)\right)$, where $U_{+}$and $U_{\square}$ are the representative utility of each option (Fig. 2B). In the Ap-Av task, the function $U_{+}-U_{\square}$ was approximated by the first-order linear model that had the lowest Bayesian information criterion (BIC; Amemori and Graybiel, 2012). We thus parameterized the function $U_{+}-U_{\square}$ as $U_{+}-U_{\square}=a_{1} x+a_{2} y+a_{3}$, where $x$ was the length of red bar, $y$ was the length of yellow bar, and $a_{1}$, $a_{2}$, and $a_{3}$ were the coefficients determined by the generalized linear model or logistic regression. We modeled each utility as $U_{+}=U_{\mathrm{AP}}=$ $a_{1} x+a_{2} y$, and $U_{\square}=U_{\mathrm{AV}}=-a_{3}$. The weighted average, $\mathrm{ChV}=p_{+} U_{+}+$ $\left(1-p_{+}\right) U_{\square}$, is interpreted as corresponding to the "chosen value" $(\mathrm{ChV})$, i.e., the anticipatory value associated with the selected option 
A

Approach-avoidance (Ap-Av) task

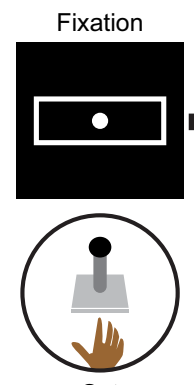

Set

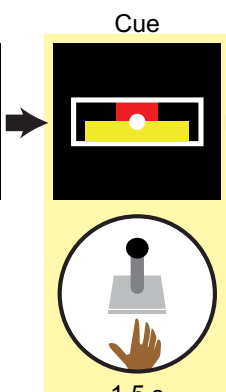

$1.5 \mathrm{~s}$

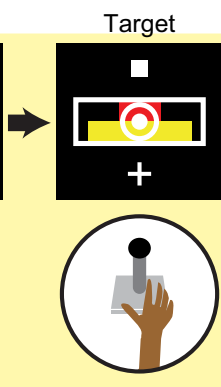

$+$

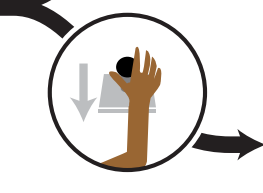

Avoid
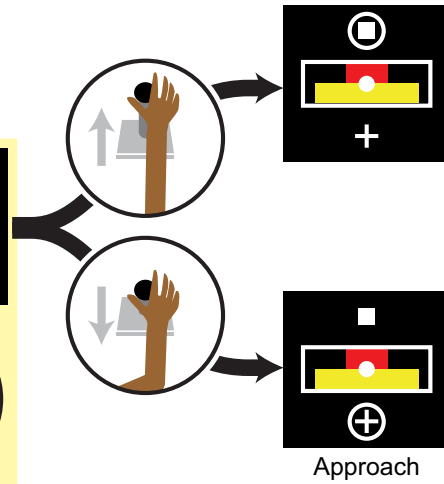

Approach

Error
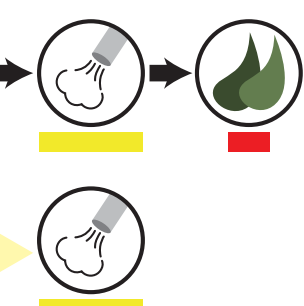

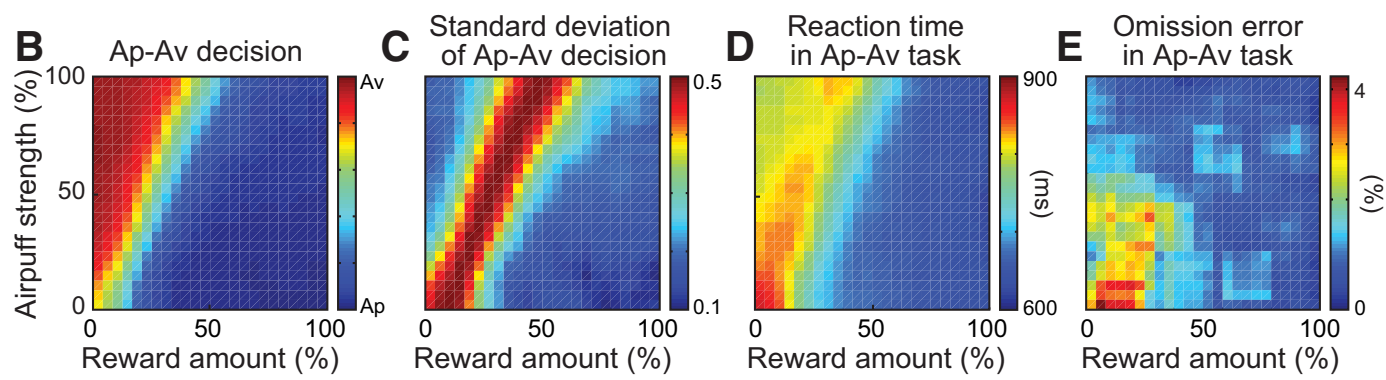

$\mathbf{F}$

Approach-approach (Ap-Ap) task
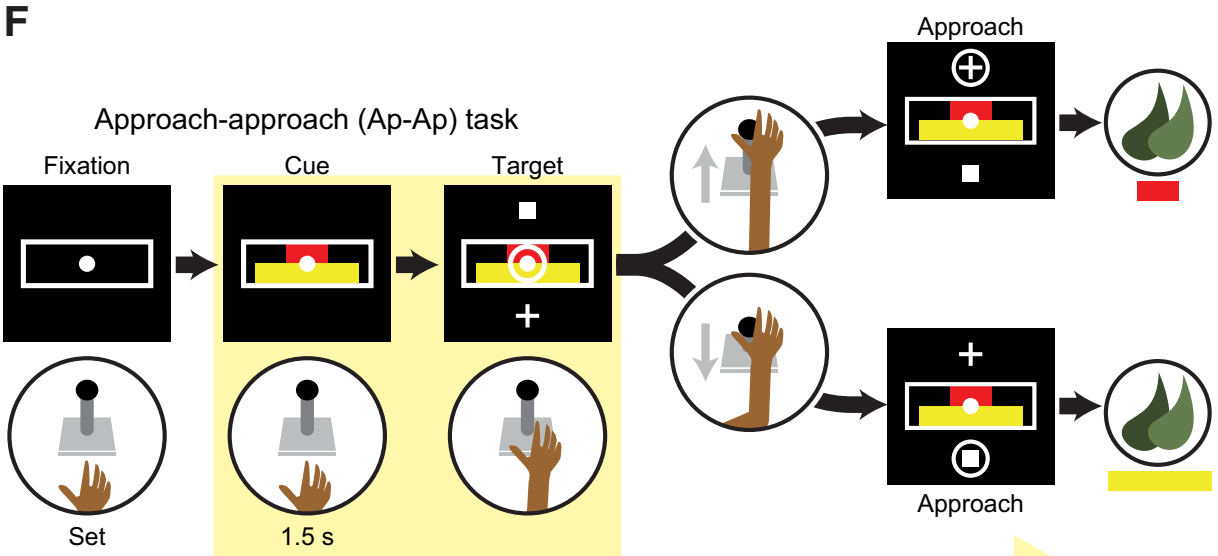

Error

No reward

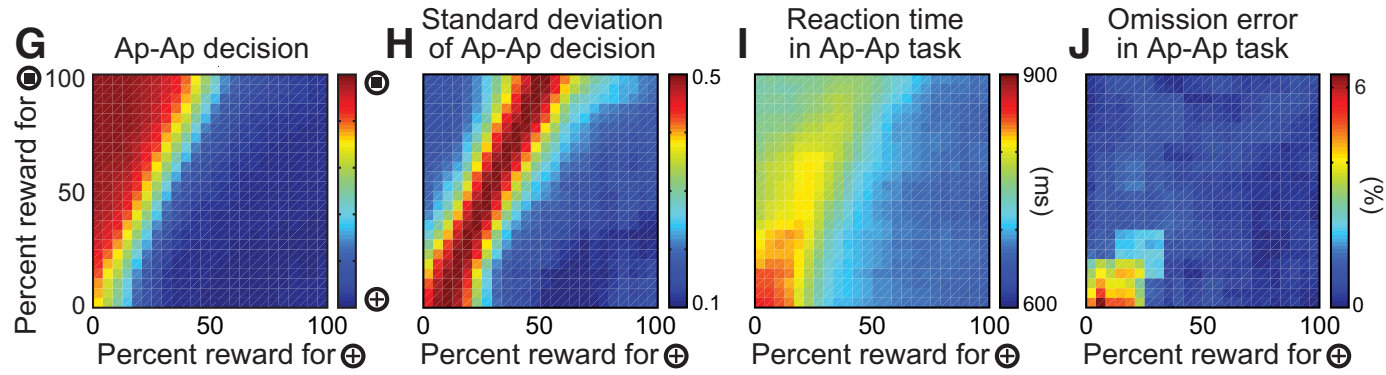

\begin{tabular}{|c|c|c|c|c|}
\hline $\mathbf{K}$ & 150 trials & 150 trials & 150 trials & 150 trials \\
\hline $\begin{array}{r}\text { single } \\
\text { session }\end{array}$ & Ap-Av & Ap-Ap & $A p-A v$ & Ap-Ap \\
\hline
\end{tabular}



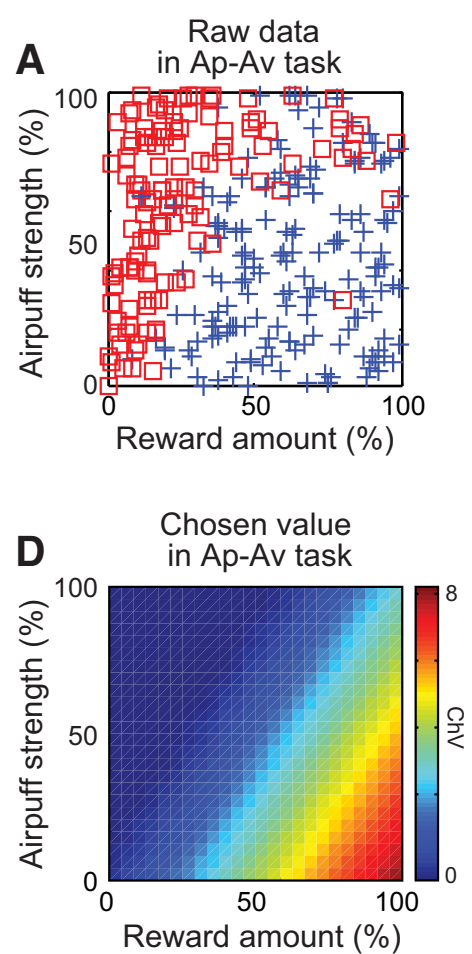
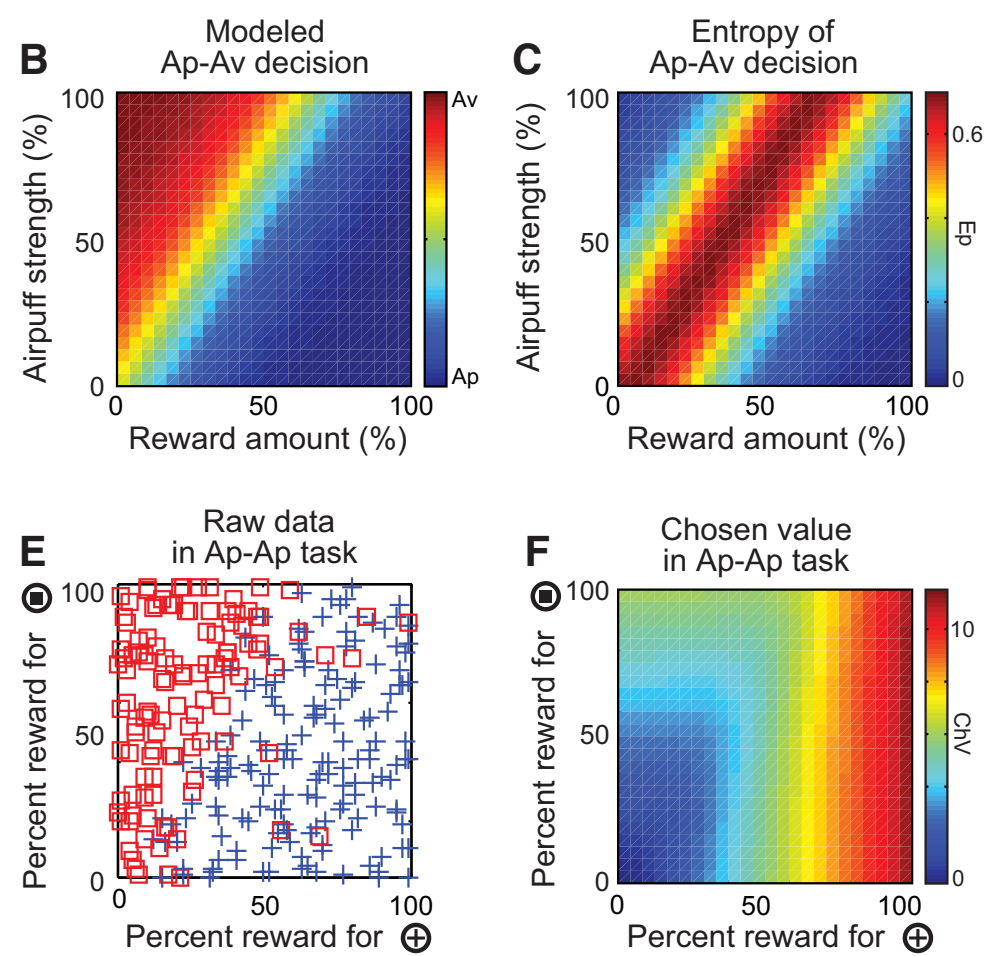

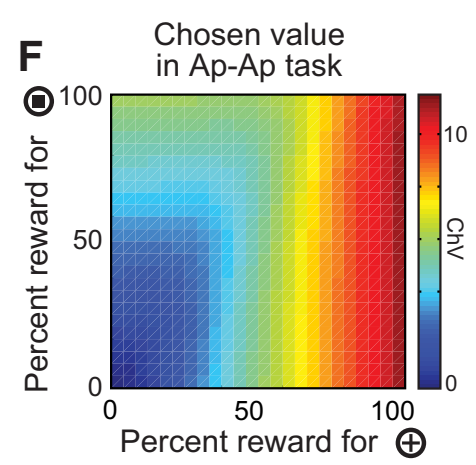

Figure 2. Parametric modeling of the decisions by monkey $S$ in a single session in the Ap-Av $(\boldsymbol{A}-\boldsymbol{D})$ and $A p-A p(\boldsymbol{E}, \boldsymbol{F})$ tasks. $\boldsymbol{A}$, Avoidance (red square) and approach (blue cross) decisions made by the monkey in a single session of the Ap-Av task. $\boldsymbol{B}$, The behavioral model derived by logistic regression with the dataset shown in $\boldsymbol{A}$. The color scale indicating the probability of choosing avoidance (red) or approach (blue) is shown at the right. $\boldsymbol{C}$, The Ep of Ap-Av decisions derived from the model. $\boldsymbol{D}$, The ChV in the Ap-Av task estimated by the expected utility and derived from the model. $\boldsymbol{E}$, Choices of square (red square) and cross (blue cross) targets during a single session of the Ap-Ap task. $\boldsymbol{F}$, The ChV in the Ap-Ap task derived from the model.

(Von Neumann and Morgenstern, 1947; Padoa-Schioppa and Assad, 2006; Fig. 2D). We consider the $\mathrm{ChV}$ in the Ap-Av task to be enhanced by the expectation of reward and to be suppressed by the expectation of punishment, because this is the parameter that reflects valuation for value-based decision-making. In the Ap-Ap task, following BIC procedures, we adopted the first-order approximation model without a bias term as the best model, $U_{+}-U_{\square}=a_{1} x+a_{2} y$, where $x$ was the length of red bar, $y$ was the length of yellow bar, and $a_{1}$ and $a_{2}$ were the coefficients determined by the logistic regression. Given that the monkeys were fully trained on this task, we considered that the monkeys had acquired the association between the cross target and the red cue and the associations between the square target and the yellow cue. Then, $U_{+}$became a func-

$\leftarrow$

Figure 1. Task flow and decisions. $A$, The Ap-Av task started when the monkey put its hand on the designated position in front of the joystick. After a $1.5 \mathrm{~s}$ fixation period, two bars appeared on the screen. The length of the red and yellow bars indicated, respectively, the offered amount of food and airpuff delivered after approach choice. After a 1.5 s cue period, the monkey could move the joystick to the cross target to indicate an approach choice or to the square target for an avoidance choice. The locations of the two targets were randomized across trials. After approach decisions, both airpuff and food were delivered in the offered amounts. After avoidance decisions, the monkey did not receive the offered airpuff and food but received the smallest amount of food. When the monkey made commission or omission error, the airpuff was delivered at the strength indicated by the length of the yellow bar. $\boldsymbol{B}$, Monkeys' decisions averaged over all 345 recording sessions in the Ap-Av task, plotted for combinations of the offered amount of reward ( $x$-axis) and the offered strength of airpuff ( $y$-axis). The color scale at the right indicates the proportion of choosing avoidance (red) or approach (blue). $\boldsymbol{C}-\boldsymbol{E}$, The SDD $(\boldsymbol{C}$, average RTs (D), and FOE (E) in the Ap-Av task. $\boldsymbol{F}$, In the Ap-Ap task, the length of the red and yellow bars corresponded to the amount of reward that the monkey could obtain after choosing cross and square targets, respectively. G, Monkeys' decisions in the Ap-Ap task, plotted for combinations of the offered amount of reward associated with cross target ( $x$-axis) and the offered amount of reward associated with the square target $(\boldsymbol{y}$-axis). $\boldsymbol{H}-\boldsymbol{J}$, The SD of the decisions $(\boldsymbol{H})$, average RTs $(\boldsymbol{I})$, and FOE $(\boldsymbol{J})$ in the Ap-Ap task. $\boldsymbol{K}$, The sequence of Ap-Av and Ap-Ap task blocks in a single recording session. The two tasks alternated every 150 trials. tion of $x$, and $U_{\square}$ became a function of $y$. Based on this assumption, we modeled $U_{+}=a_{1} x$ and $U_{\square}=-a_{2} y$. Based on the decisions in each session (Fig. $2 E$ ), we calculated the chosen value by $\mathrm{ChV}=p_{+} U_{+}+(1-$ $\left.p_{+}\right) U_{\square}$, where $p_{+}$is the probability of choosing the cross target, estimated by logistic regression (Fig. $2 F$ ). In both the Ap-Av and Ap-Ap tasks, the entropy of the decisions (Ep; Fig. $2 C$ ) was calculated by the model as Ep $=-p_{+} \log p_{+}-\left(1-p_{+}\right) \log \left(1-p_{+}\right)$.

Behavioral parameters to characterize the decision-making process. To characterize parametrically the behavior and the decision-making process, we began with 11 variables. Among them, seven variables-the offered reward (the amount of offered reward indicated by the red bar; Rew), the offered airpuff (the offered pressure of airpuff indicated by the yellow bar; Ave), the binary value of approach (1) or avoidance (0), the chosen reward (the amount of reward that would be delivered after the choice of approach; ChR), the chosen aversion (the strength of airpuff that would be delivered after the choice of approach; ChA), the reaction times (RTs), and the direction of the joystick movement (push or pull; Mv)—were derived directly from the monkey's performance in each recording session. We also used four hypothetical variables to characterize the process of the decision-making. Two of these, ChV and Ep, were derived from the econometrics model calculated for each session. Two other variables, SD of decision (SDD) and the frequency of omission error (FOE), were derived from the corresponding averaged behavioral parameters. Omission errors were counted as trials in which the monkey did not respond during the $3 \mathrm{~s}$ response period.

Because of the limited number of omission errors in single sessions, we did not use these parameters as obtained from single sessions. Instead, we adopted the mean of SDD and the mean of FOE derived by averaging these variables over all recording sessions. The mean of SDD and the mean of FOE were parameterized by the combined offers as shown in Figure $1, C, E, H$, and $J$. To calculate the pattern of choice (Fig. $1 B, G$ ), SDD (Fig. $1 C, H$ ), RT (Fig. $1 D, I$ ), and FOE (Fig. $1 E, J$ ), each datum parameterized by the combined offers was convolved with $4 \times 4$ square and assigned into $25 \times 25$ matrix. Thus, FOE was not a variable measuring the omission error in a given trial but was correlated with conditions 
that frequently induced the omission errors. We considered that FOE was inversely correlated with the level of motivation to perform the task. We used the Ep and SDD to characterize the degree of conflict in the Ap-Av task. Parameters derived from the averaged behavioral patterns (FOE and SDD) were obtained from the corresponding value in the matrix (Fig. 1C,E). Thus, the 11 behavioral parameters were obtained for each trial.

Before calculating the k-means clustering (see Fig. $4 B$ ) and the population activity (see Figs. 6-8, 10,11), every dataset was "standardized" so that we could compare behavioral parameters and the unit activities across different daily sessions. Following the method described previously (Amemori and Graybiel, 2012), we linearly resized the reward amount to have the same decision boundary across different recording sessions.

Preparatory analyses to select explanatory variables for regression. Some of these 11 variables used originally to parametrically describe the behavior above could clearly have been correlated with one another, reducing their value as explanatory variables for regression analysis (the multicollinearity problem). To select the variables necessary and feasible for multivariate regression analyses among these, we therefore performed two preparatory analyses, correlation analyses and a clustering procedure. First, we performed correlation analyses with all task-related units (Fig. $4 A)$. For each unit, the variable that exhibited the highest correlation coefficient with the cue-period activity among the 11 variables was defined as the "feature variable" for that unit. We ranked the 11 variables by the number of units with activity showing significant correlation with them as determined by Pearson's correlation coefficients $(p<0.05)$. We found that Rew, Ave, ChV, RT, and FOE were ranked as the top five. These five were the feature variables for $72 \%$ (1029 among 1431 units) of the task-related units, suggesting that they were important explanatory variables to use in characterizing the dataset.

Second, to support further the validity of the selected five variables, we inserted a clustering procedure (Fig. $4 B$ ). Because the multicollinearity problem is produced by similar regression variables, we aggregated the similar units and then chose one representative variable for the groups of similar units. We used $k$-means clustering to group the similar units. After we standardized the data to compare across the sessions (Amemori and Graybiel, 2012), for unit $i$, we produced an $8 \times 8$ matrix, $m_{i}(x, y)$, where $x$ and $y$ were the corresponding sizes of reward and airpuff, respectively. For each combination of $x$ and $y$, the mean firing rate was calculated and assigned to the corresponding element. The distance (or dissimilarity index) between unit $i$ and $j, D(i, j)$, was represented by $1-$ $r_{i j}$, where $r_{i j}$ indicated the two-dimensional correlation of $m_{i}(x, y)$ and $m_{j}(x, y)$. We used classical multidimensional scaling (or principal coordinates analysis) to compress the representation of the dissimilarity matrix, $D(i, j)$, in which the activity of unit $i$ was represented by extracted common features parameterized by $f$. We performed the $k$-means clustering with the scaled dissimilarity matrix, $D(i, f)$, with different numbers of clusters $(k=1$ to $k=100)$ and with 1000 different initialization parameters for each $k$. Thus, we derived 62 optimal clusters that had the lowest sum of silhouette value (Rousseeuw, 1987). For each unit in the cluster, we performed a correlation analysis between 11 hypothetical parameters (Rew, Ave, Cho, ChV, ChR, ChA, Ep, SDD, RT, FOE, and $\mathrm{Mv}$ ) and the cue-period activity of units in the cluster. The correlation analysis was performed on a trial-by-trial basis using a single epoch that covered the entire $1.5 \mathrm{~s}$ cue period. For each cluster, we chose the variables that had a significant correlation (Pearson's correlation coefficient, $p<0.05)$ most frequently as the feature variable of the cluster. As a result, most of the clusters (51 among 62 clusters, $82 \%$ ) were characterized by the five variables (Rew, Ave, ChV, RT, and FOE), suggesting that these five variables were the representative features to characterize most of the clusters of similar units. With the two analyses, we thus confirmed that the five variables were selected robustly as the important explanatory variables for the regression analyses.

Lastly, to confirm that the five selected variables were suitable for the multivariate regression, we performed multicollinearity checks for each recording session using the Belsley's collinearity test (Belsley et al., 1980). In our dataset, there were no sessions in which the set of variables exceeded the standard tolerance (a variance decomposition proportion
$>0.5$ and a condition index $>30$, established in the collinetest function of MATLAB), indicating that these combinations were feasible for the multivariate regression.

All possible subset regression for neuronal classification. To classify units, we focused on the cue period, during which the monkeys could make a decision based on the offer indicated by the cues but during which they did not yet know the direction of movement required to indicate their decision. With the cue-period activity for the Ap-Av task, we performed the all-possible subset regression analysis using the five selected explanatory variables (Rew, Ave, ChV, RT, and FOE). For every possible combination of the variables (31 combinations), we performed regression to characterize the cue-period activity of each unit on a trial-by-trial basis. The cue-period activity was defined by the raw spike count divided by the cue-period length. Both the cue-period activity and the explanatory behavioral variables were obtained for each trial. For each unit, the bestfitted model was selected among all possible combinations based on BIC (Fig. 5A). Among the combinations of variables that explained the cueperiod activity significantly well $(p<0.05)$, the combination that produced the highest BIC score was selected. We also applied Akaike information criteria and Mallow's $C p$ statistic as the criteria for the model selection and confirmed that the proportion of each category was similar among all criteria (Fig. 5C). Furthermore, we also performed stepwise regression with the stepwisefit function of MATLAB. With the stepwise regression analyses, we could add and remove terms from a multiple linear model based on a series of $F$ tests. At each step, the $p$ value of an $F$ statistic was computed to test models with and without the indicated term. We performed the stepwise regression algorithm, beginning with no terms in the model and using entrance/exit tolerances of $0.05 / 0.10$ on the $p$ values. The results of stepwise regression were also similar to the results of all-possible subset regression (Fig. $5 C$ ), suggesting a robustness of the results against different criteria.

\section{Results}

\section{Behavioral correlates of conflict and reluctance in task performance}

The Ap-Av and Ap-Ap tasks performed by monkeys A and S are illustrated in Figure 1. In the Ap-Av task, the monkeys' decisions were determined systematically based on Rew and Ave (Fig. 1B). The SDD was high along the decision boundary, suggesting a conflict state in decision-making at this boundary (Fig. $1 C$ ). The RT was also of relatively long duration along the decision boundary, but it was clearly affected by the sizes of Rew and Ave (Fig. $1 D)$. When the Rew and Ave were small, RTs were longest, suggesting a low motivational state and a reluctance to perform the task under low payoff conditions. In the Ap-Ap task (Fig. 1F-J), the monkeys chose the option that gave the larger reward. Because the unit amount of reward associated with the unit length of the red bar was twice as large as that indicated by the yellow bar, the decision boundary in the Ap-Ap task corresponded to the offers for which either choice resulted in the same amount of reward. When the offered reward sizes were both low, the RTs were the longest, suggesting low motivation to perform the task (Fig. 1I). The pattern of the RTs in the Ap-Ap task was similar to that in the Ap-Av task. In both tasks, the RTs were longest for "low-low" combined offers (i.e., low reward and low airpuff offers in the Ap-Av task or low reward offers for both targets in the Ap-Ap task; Fig. $1 D, I$ ). Thus, we interpreted the RT as a compound of conflict and low motivational states in task performance and that the pattern of this compound was similar in the two tasks.

\section{Dissociation of motivation and affective judgment}

The affective judgments leading to acceptance and rejection of combined offers are determined by integration of positive and negative values of the offer, but they also induce motivational responses that affect the decision-making process. In an attempt 
to dissociate neural activity related to affective judgment and motivation, we introduced two hypothetical variables. First, we focused on the FOE as a key behavioral parameter to quantify the level of motivation (Fig. 1E). Omission errors occurred when the monkey did not respond during the $3 \mathrm{~s}$ response period. When the monkeys made an omission error, the trial was terminated by the delivery of a penalty airpuff whose strength was associated with the length of the yellow bar (Fig. 1A). When the monkeys did not want to receive the penalty airpuff, they had to actively choose the avoidance target. Therefore, the FOE decreased as either the Rew or the Ave increased. In fact, in both the Ap-Av and Ap-Ap tasks, the FOE was the highest for low-low combined offers (i.e., low reward and airpuff offers in the Ap-Av task or low reward offers in the Ap-Ap task; Fig. 1E,J). We interpreted the FOE as a behavioral parameter that is correlated with a low motivational condition (Roesch and Olson, 2004) and used it as the explanatory variable to define units related to low motivation. In accordance with this interpretation, we found that the FOE in the Ap-Av task was decreased by increased expectation of reward and punishment (Fig. 1E), whereas the FOE in the Ap-Ap task was increased by decreases in the size of the offered rewards (Fig. $1 J$ ).

Second, to characterize quantitatively the affective judgment of whether to accept or to reject the combined offer, we introduced a computational model (conditional logit) that estimated the $\mathrm{ChV}$. In the Ap-Av task, the ChV increased linearly according to the size of offered reward and decreased linearly according to the strength of the airpuff (Fig. 2D). In contrast, in the Ap-Ap task, the ChV was determined by the larger of the two reward amounts offered by the red and yellow bars (Fig. 2F). Therefore, the $\mathrm{ChV}$ differed between the Ap-Av and Ap-Ap tasks. The reward and punishment differentially affected the FOE and $\mathrm{ChV}$ in the Ap-Av task and allowed us to dissociate estimated internal neuronal processes related to affective judgment and motivation.

\section{Classification of units}

We isolated 3109 neocortical units, of which 1076 were recorded from the right and left dlPFC of the two monkeys (689 from monkey A, 387 from monkey S; Fig. 3, blue circles) and 2033 units from the ACC of both sides (1143 from monkey A, 890 from monkey S; Fig. 3, red circles). The analytical results using approximately half of the ACC units (1065 units, 52.4\% of the current dataset) were reported previously (Amemori and Graybiel, 2012), so that approximately the same numbers of units were newly recorded in the ACC and dlPFC. Among the dlPFC units, $904(84.0 \%)$ were defined as task related, because their firing rates during the cue period were significantly different from those during the $1 \mathrm{~s}$ time window before the fixation cue appeared (twosample $t$ test, $p<0.05$ ) and those during the pre-cue period (two-sample $t$ test, $p<0.05$ ). Among the ACC units, 1760 units $(86.6 \%)$ were defined as task related by the same criterion. To classify the full population of 2664 task-related units, we performed all possible subset regression with BIC. First, we selected five explanatory variables (Rew, Ave, ChV, RT, and FOE) based on the results of correlation analyses (see Materials and Methods; Fig. 4). We performed regression analyses with the cue-period activity in the Ap-Av task for all possible combinations of the five explanatory variables, and we selected the combination of the variables that had the highest BIC score. Among all task-related units, $53 \%$ were significantly well accounted for $(p<0.05)$ by the regression models produced by the single or combinations of the variables (1409 units; Fig. 5A). Among these, 81\% (1142 units) were characterized by single variables. In additional analyses, we use these 1142 classified units as the sets of dIPFC and ACC units with cue-period activity that could be accounted for $(p<0.05)$ by the explanatory variable parameters that we introduced (Fig. $5 B$ ). Thus, our database was confined to the units that could be identified according to the regression analysis with BIC, which was based on the firing properties recorded during performance of the Ap-Av task.

\section{Properties of units encoding Rew and Ave}

Among all classified units, 486 units (43\%) were classified as units encoding offered values (Rew and Ave). The cue-period activity of Rew + units was linearly and positively correlated with the size of offered reward (Fig. $6 \mathrm{~A}$, top left), and these units were observed significantly more frequently in the ACC ( $n=127,16.9 \%$ of all classified ACC units) than in the dlPFC ( $n=46,11.8 \%$ of all classified dlPFC units; Fisher's exact test, $p<0.05$; Fig. $6 A$ ). Units that had activity correlated negatively with the offered reward (Fig. 6B, Rew-) did not show any bias in proportion between the 


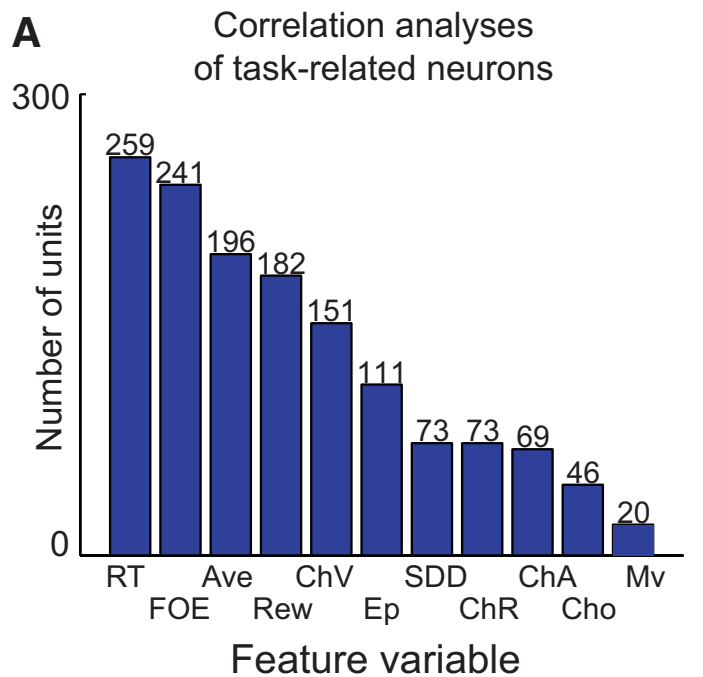

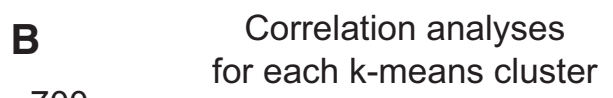

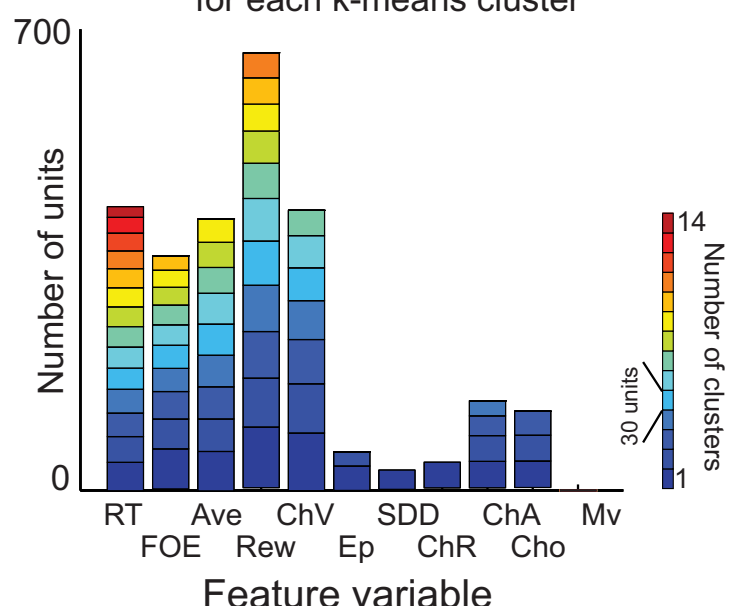

Figure 4. Procedure to select explanatory variables for regression analyses. Among 11 variables arbitrarily derived (Rew, Ave, ChV, Cho, ChR, ChA, RT, SDD, Ep, FOE, and Mv), we selected five variables (Rew, Ave, ChV, RT, and FOE). Both correlation $(\boldsymbol{A})$ and $k$-means clustering $(\boldsymbol{B})$ analyses ranked these as the top five variables that accounted for the unit properties. $\boldsymbol{A}$, The correlation analyses were performed between the cue-period activity of each task-related unit and 11 variables. The feature variable for each unit was defined by the variable that exhibited the lowest $p$ value for the Pearson's correlation coefficient among the 11 variables. The number of units with activity showing significant correlation ( $p<0.05 ; y$-axis) was shown for an individual feature variable (x-axis). $\boldsymbol{B}$, The $k$-means algorithm lumped the units with similar activity without previous assumptions. For each cluster, the feature variable was defined as the variable that showed significant correlation $(p<0.05)$ with the activity of each unit in the cluster most frequently among the 11 variables. Each block represents a cluster, with the height of the block indicating the number of units in the cluster and the color of the block reflecting the number of clusters for the feature variable (small, bluish; large, reddish).

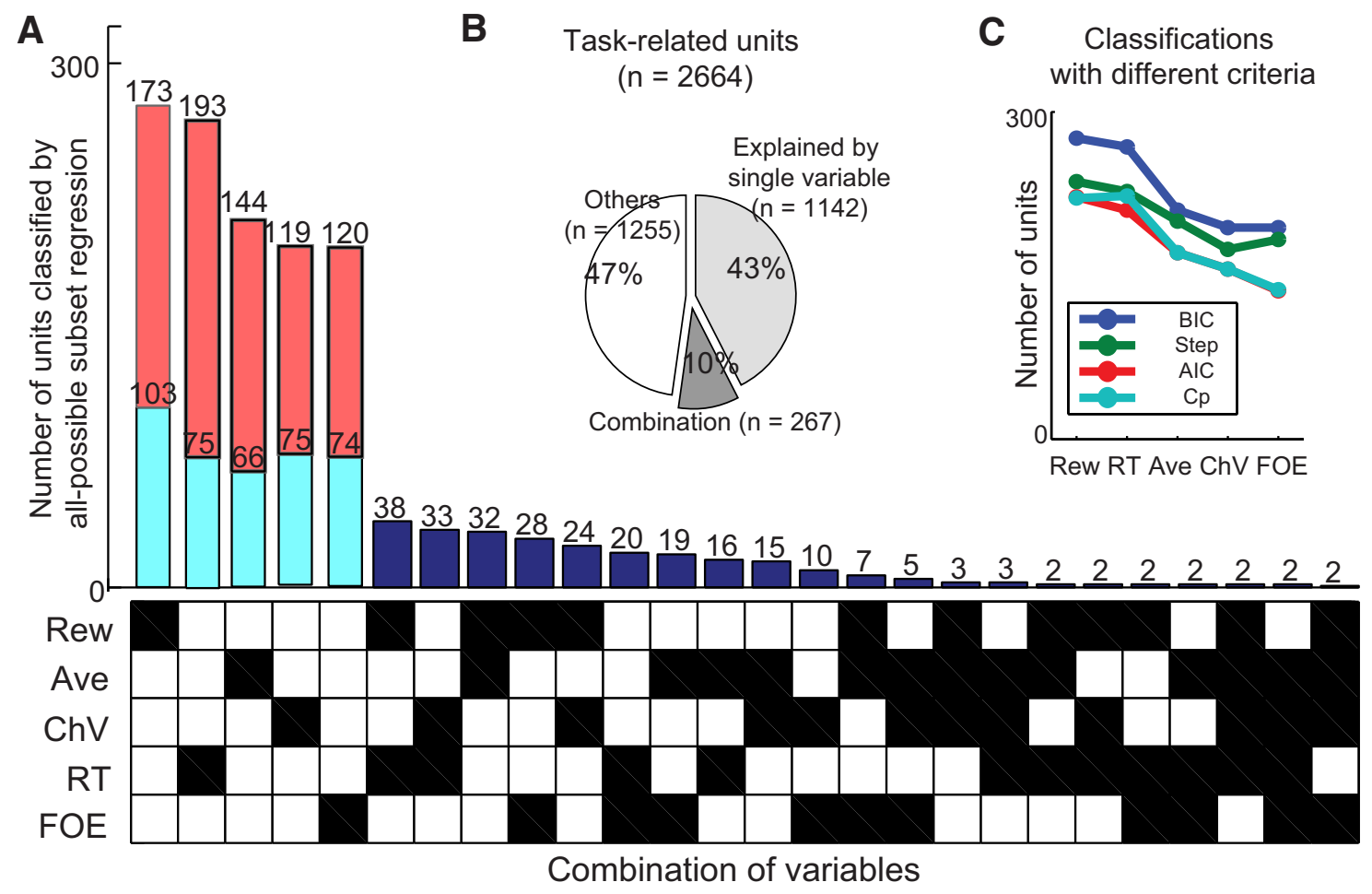

Figure 5. Unit classification. $\boldsymbol{A}$, The number of units classified by the all-possible subset regression. Regression analyses for the cue-period activity were performed with all-possible combination of the five explanatory variables (Rew, Ave, ChV, RT, and FOE). The best combination of variables was selected based on BIC. The 1142 units explained by single variables were further separated into units with activity that was correlated positively (orange) or negatively (cyan) with the variable. Another 267 units were characterized by particular combinations of variables indicated by black squares in the matrix. $\boldsymbol{B}$, The proportion of task-related units explained by single (43\%) and combination (10\%) of variables. C, Classification of units with all-possible subset regression analyses performed with different criteria (blue, BIC; red, Akaike information criteria; cyan, Mallow's (p statistic) and with stepwise regression analyses (green). All analyses similarly categorized units with the five selected variables.

ACC and dlPFC regions analyzed. In a similar way, units with activity correlated linearly and positively with the offered strengths of the airpuff were categorized as Ave + units (Fig. $6 C$, top left). Ave + units were observed significantly more frequently in the ACC ( $n=109,14.5 \%$ of all classified ACC units) than in the dlPFC ( $n=35,8.9 \%$ of all classified dlPFC units; Fisher's exact test, $p<0.05)$. Units with activity correlated negatively with offered airpuff were categorized as Ave- units (Fig. 6D). The 
A
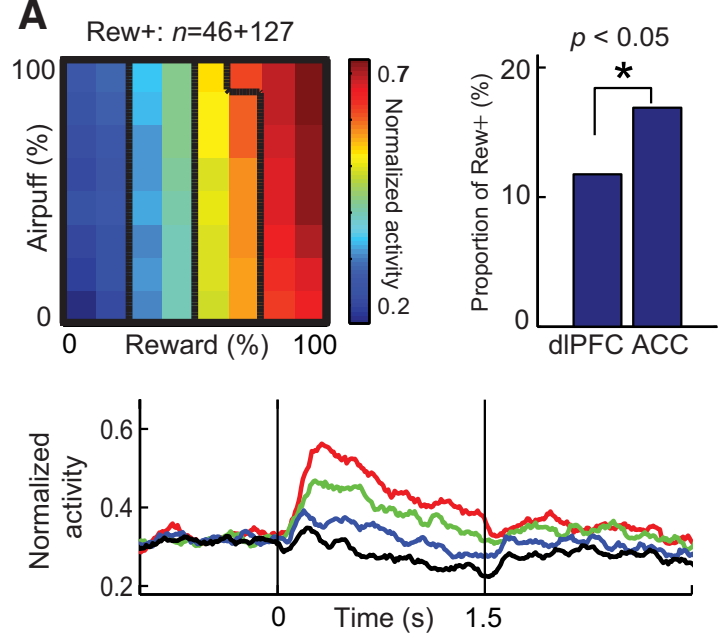

C
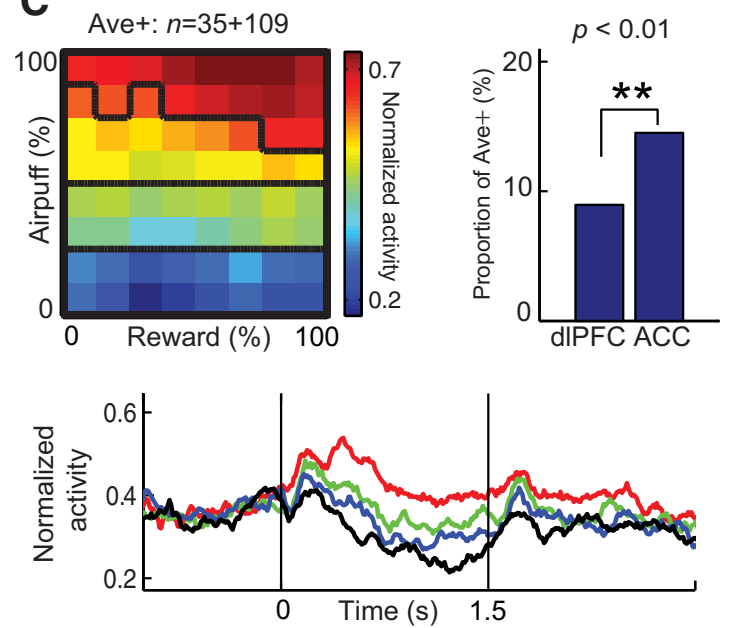
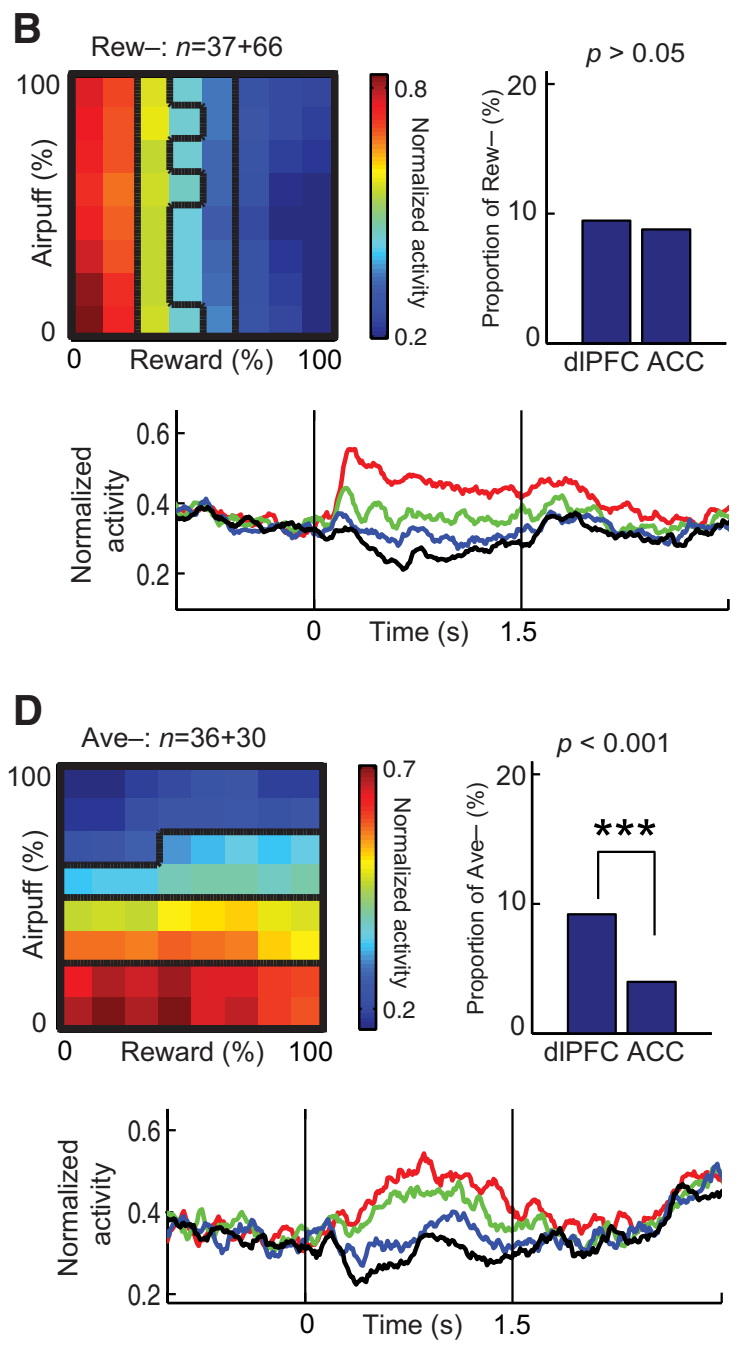

Figure 6. Properties of units with positive (Rew,$+ \boldsymbol{A})$ or negative (Rew,$- \boldsymbol{B})$ correlations with offered reward and those with positive (Ave,$+ \boldsymbol{C}$ ) or negative (Ave,$- \boldsymbol{D})$ correlations with offered aversion . In each panel, the top left shows the population activity relative to the offered amounts of reward ( $x$-axis) and air puff $(y$-axis). The cue-period activity of each neuron was binned to an $8 \times 8$ matrix and normalized by the formula [Rate - $\min ($ Rate)]/[max(Rate) - min(Rate)], where Rate indicates the firing rate of each element in the matrix. Black contours divide the normalized activity into four quartiles. The numbers of units in the dIPFC and ACC are indicated, respectively, at the left and right of the plus sign. The top right shows the proportion of each type among all classified dIPFC and ACC units. The bottom shows the normalized activity around cue onset (time 0 ) for cue combinations that induced activity in the top (red), second (green), third (blue), and bottom (black) quartiles as defined in the top left. ${ }^{*} p<0.05$, ${ }^{* *} p<$ $0.01,{ }^{* * *} p<0.001$ (Fisher's exact test).

dlPFC population contained more of these units than did the ACC population (Fig. 6D).

\section{Properties of units encoding $\mathrm{ChV}$ and $\mathrm{RT}$}

Units with cue-period activity that was correlated with the ChV were notable, because these units encoded the anticipated value of the chosen option. In contrast to the Rew and Ave units, these units did not reflect objectively the offered reward value, but rather reflected the monkey's subjective evaluation (PadoaSchioppa and Assad, 2006). The units with activity positively correlated with the $\mathrm{ChV}$ were classified as $\mathrm{ChV}+$ units (Fig. 7A). Their activity increased as the offered reward increased and as the offered airpuff decreased, showing positive correlation with the monkey's acceptance decisions. Conversely, the units with activity negatively correlated with the $\mathrm{ChV}$ were classified as $\mathrm{ChV}-$ units (Fig. $7 B$ ), and their activity was positively correlated with the monkey's rejection decision. We found no regional bias in their proportions in the ACC and dlPFC (Fig. 7 A, B, top left).

Among all classified units, 268 units were classified as RT units. The units with activity positively correlated with the RT on a trial-by-trial basis were classified as RT + units (Fig. 7C). The dlPFC population ( $n=80,20.5 \%$ of all classified dlPFC units) contained significantly more RT + units (Fisher's exact test, $p<$ $0.05)$ than the ACC population $(n=113,15.0 \%$ of all classified ACC units; Fig. $7 C$, top right). In contrast, units with activity correlated negatively with RT were classified as RT - units (Fig. $7 D$ ). These units did not exhibit significant biases in proportion (Fig. 7D, top right). Interestingly, the upcoming RT in the response period was predicted by the activity of the RT units even before the cue period. The differential activity of RT units appeared before the cue period (Fig. $7 C, D$, bottom), suggesting that the activity was not dependent solely on the offered cue but could also be modulated by long-term motivational states.

\section{Properties of units encoding motivation}

We regarded the condition that frequently induced omission errors as a low motivational condition (Hassani et al., 2001; Watanabe et al., 2001; Roesch and Olson, 2004). Units with activity positively correlated with the FOE were categorized as FOE+ units. These units were specifically activated in the low-low con- 
A
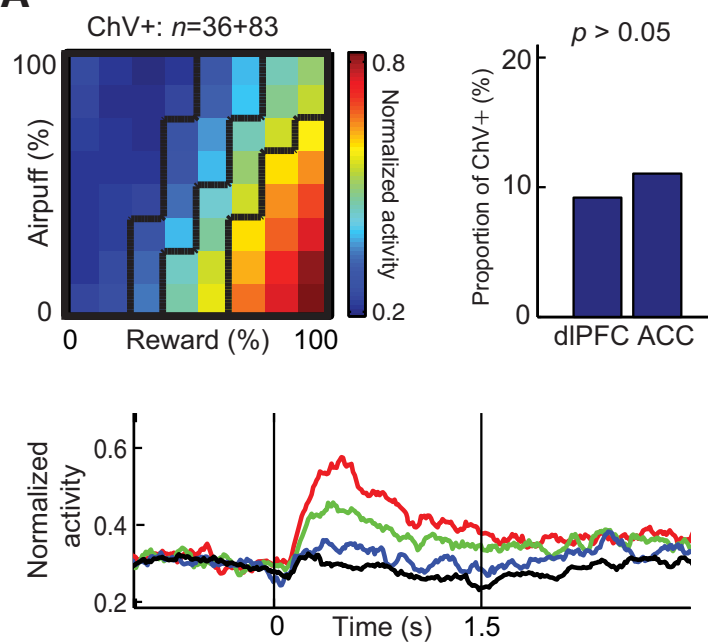

C
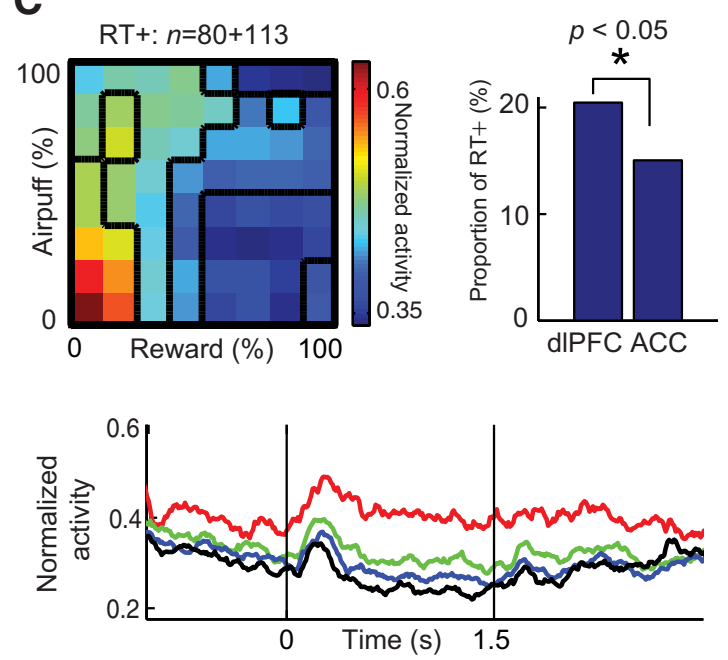

B
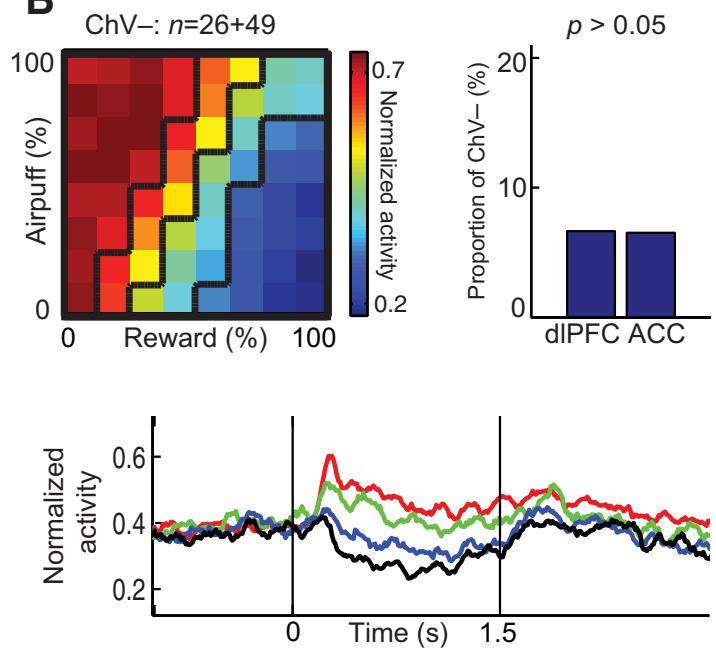

D
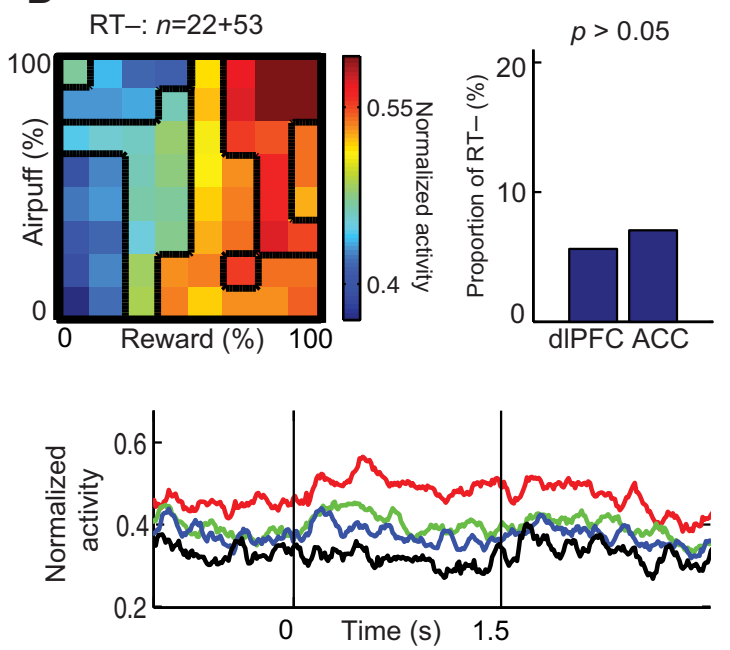

Figure 7. Properties of units showing positive $(\mathrm{ChV}+, \boldsymbol{A})$ or negative $(\mathrm{ChV}-, \boldsymbol{B})$ correlations with ChV and those with positive (RT+, $\boldsymbol{C})$ and negative (RT-, $\boldsymbol{D})$ correlations with $\mathrm{RT}$. Normalized population activity (top left), the proportion of each type of units in the dIPFC and ACC (top right), and the temporal pattern of the population activity (bottom) are illustrated as in Figure 6. The proportion of RT + units in the dIPFC was significantly larger than that in the ACC ( ${ }^{*} p<0.05$, Fisher's exact test).

dition in which the Rew and Ave were both small. Occasional deferment of the task performance reflects a state in which the monkey reluctantly performed the decision-making. Like the proportion of RT + units, which were also correlated with the low motivational state, the proportion of the $\mathrm{FOE}+$ units in the dlPFC was significantly larger than that in the ACC (Fisher's exact test, $p<0.05$; Fig. $8 A$, top right). Units with activity negatively correlated with FOE were categorized as FOE - units. These neurons were activated when either the reward or airpuff offer was high, reflecting the activity in the high motivational condition to perform the decision-making (Fig. $8 B$ ).

To estimate whether the dIPFC or the ACC temporally led in neuronal processing related to motivational regulation, we compared the time when the neuronal activity in each region began to discriminate the motivational conditions. For FOE + and FOEunits, the high and low motivational conditions were defined, respectively, as having offered cues that induced higher and lower firing rates than the median in population activity (Fig. $8 A, B$, top left). For the high and low motivational conditions, neuronal spikes were sampled in $10 \mathrm{~ms}$ bins. With these data, the discriminative ability between the two conditions was determined by a
Wilcoxon's rank-sum test with 200 ms sliding windows and was represented by a $z$ value. When the neuronal activity showed a significant difference $(p<0.05)$ between the two conditions for more than eight consecutive $10 \mathrm{~ms}$ bins, we defined the time as the onset of the discrimination.

Among 194 FOE units, 53 in the dlPFC units and 84 in the ACC units exhibited significant differences in firing rate between the high and low motivational conditions (Fig. 8C). Comparing ACC and dlPFC units, we found significant differences in both the cumulative distributions of the onset of representation (Kolmogorov-Smirnov test, $p<0.01$ ) and the temporal distribution of onset (Wilcoxon's rank-sum test, $p<0.05$ ), suggesting that the dlPFC temporally leads the ACC in motivational regulation (Fig. $8 D, E)$. The onset distributions were not significantly different between the dIPFC and ACC for the other groups of units (Rew, Ave, $\mathrm{ChV}$, and RT units; $p>0.05$ with Kolmogorov-Smirnov and Wilcoxon's rank-sum tests). These results suggest that, although the temporal patterns of activity in the dlPFC and the ACC were generally similar, activity in the dlPFC led activity in the ACC, possibly to regulate motivational aspects of the decision-making. 
A
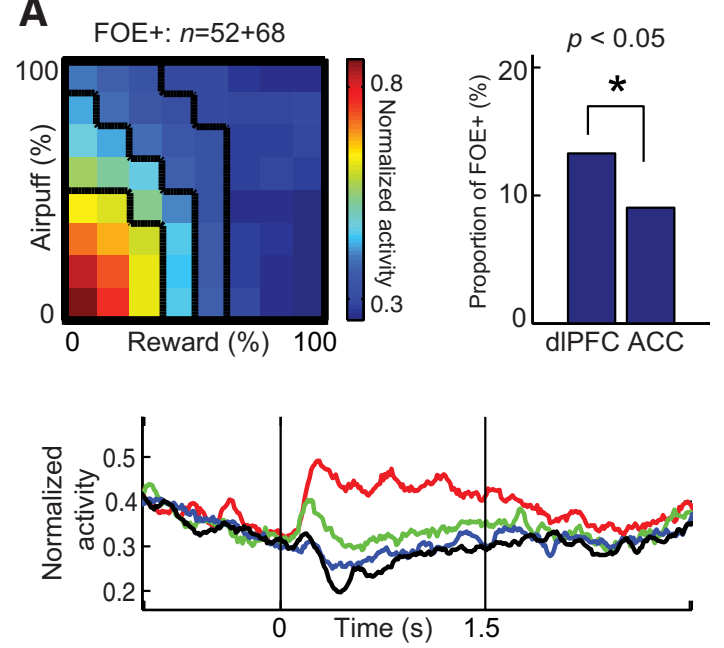

B
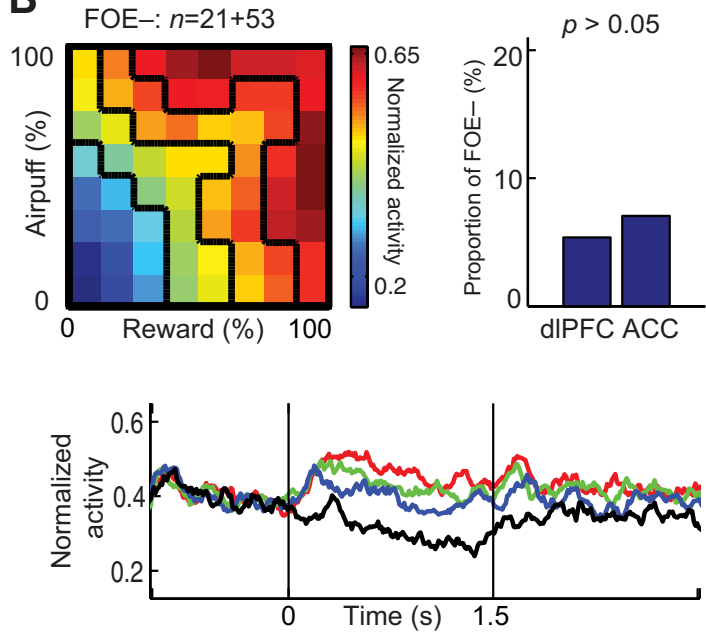

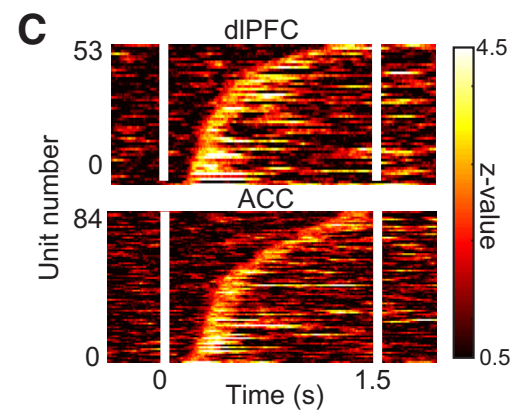

D

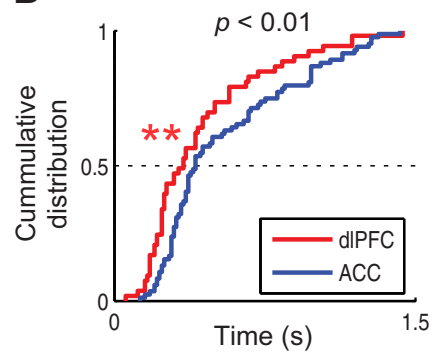

E

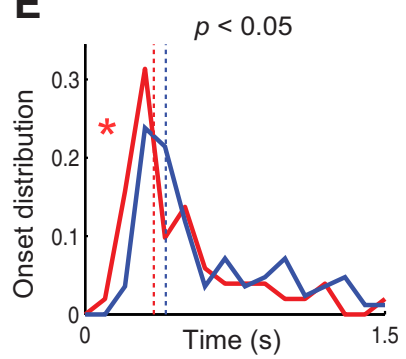

Figure 8. Properties of motivation-type units. $A, B$, Normalized population activity (top left), proportion in the dIPFC and ACC (top right), and temporal pattern of the normalized activity (bottom) of low $(\mathrm{FOE}+, \boldsymbol{A})$ and high $(\mathrm{FOE}-, \boldsymbol{B})$ motivation units, illustrated as in Figure 6. The proportion of FOE + units in the dIPFC was significantly larger than that in the ACC $\left(^{*} p<0.05\right.$, Fisher's exact test). C, Discrimination of motivational conditions by individual dIPFC (top) and ACC (bottom) units. Color indicates the $z$ value representing the degree of discrimination between low and high motivational conditions, which was defined by the preferred (top 2 quartiles) and nonpreferred (bottom 2 quartiles) cue combinations shown in the top left in $\boldsymbol{A}$ and $\boldsymbol{B}$. D, $\boldsymbol{E}$, Cumulative (D) and time-plot $(\boldsymbol{E})$ distributions of discrimination onsets of the dIPFC (red) and ACC (blue) units. The discrimination onset was significantly earlier in the dIPFC than in the ACC in both cumulative (Kolmogorov-Smirnov test, ${ }^{* *} p<0.01$ ) and time-plot (Wilcoxon's rank-sum test, ${ }^{*} p<0.05$ ) distributions. The median onset for the dIPFC population was $60 \mathrm{~ms}$ earlier than that for the ACC population.

\section{Effect of low motivation on neuronal activity}

One of the features of motivational regulation that could be observed behaviorally was the temporal dynamics of the task performance. Given that the monkeys' decisions were delayed, and occasionally were deferred, in the low motivational states, it was possible that neuronal processes related to decision-making could also be regulated by these different motivational conditions (Tversky and Shafir, 1992; Diederich, 2003). To address this issue with our dataset, we examined neural activity according to the differential motivational conditions (Fig. 9A-C). First, we defined the low and high motivational conditions as, respectively, the preferred and nonpreferred conditions of the FOE + units. We then compared the onset of discrimination between acceptance and rejection encoded by the $\mathrm{ChV}$ units in the low and high motivational conditions. The discrimination between upcoming acceptance and rejection was calculated by a Wilcoxon's ranksum test (Fig. 9A). The onset of discrimination was defined as in Figure 8C. Among $194 \mathrm{ChV}$ units, the activity of 118 units reached the criterion defining the onset in the high motivational condition, whereas the activity of 48 units reached the criterion in the low motivational condition. In both cumulative (Fig. $9 B$ ) and temporal (Fig. 9C) distribution of onsets, the discrimination was significantly earlier in the high motivational condition than in the low motivational condition (Kolmogorov-Smirnov test, $p<0.01$; Wilcoxon's rank-sum test, $p<0.05$ ). These results suggest that the low motivational condition in which the monkey occasionally deferred the decision-making actually delayed the neuronal process of deriving affective judgment.

The FOE units were defined as the units that were differentially activated by the motivational condition in which the monkey performed the decision-making reluctantly or willingly. However, because the low motivational condition was defined by the increased FOEs, it was still possible that the FOE units could be involved specifically in disengagement or omission of the task performance rather than motivational regulation. To test this possibility, we isolated a group of units that had activity directly correlated with omission of task performance. Among all taskrelated units, the cue period activities of 36 units exhibited significant differences between omission error and correct task performance (two-sample $t$ test, $p<0.05$ ), and those units were defined as omission type (Fig. 9D). Notably, these units did not overlap with the motivation (FOE) units at all (Fig. 9E), indicating a clear distinction between omission-type and FOE units. Thus, the FOE + units seemed not to be directly related to omission of task performance itself when compared with the omission-type units, yet they were activated in the low motivational condition in which the monkey correctly performed the task. Thus, the activity of $\mathrm{FOE}+$ units could reflect motivational regulation to perform the task patiently in the low payoff condition. 

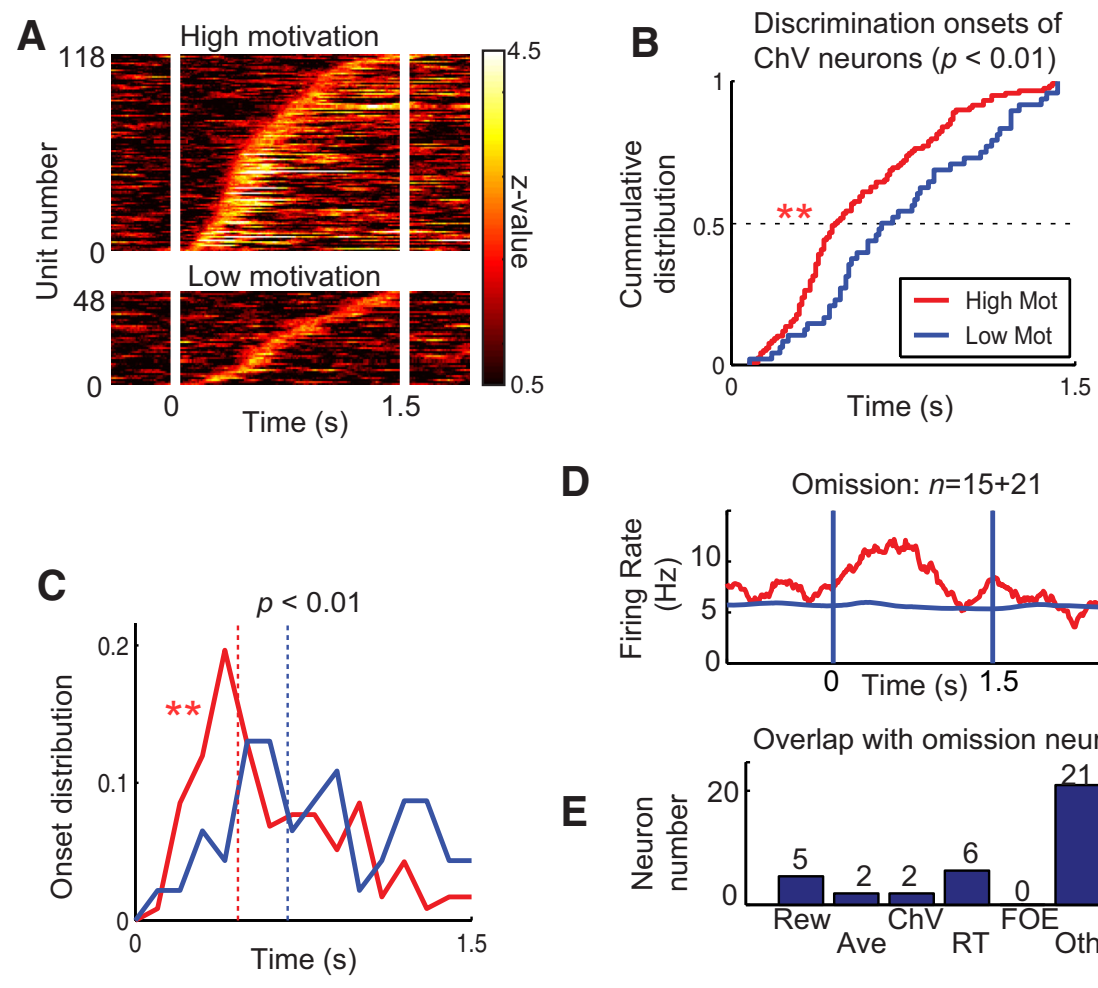

D
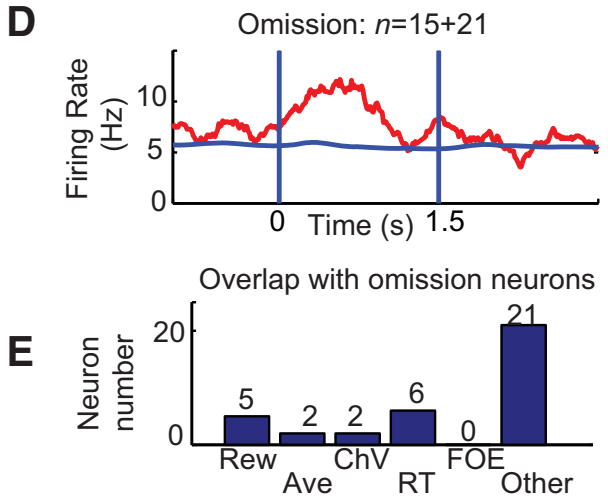

Figure 9. Effects of low motivation on neuronal activity. $A$, Discrimination of upcoming acceptance and rejection by $C h V$ units in high (top) and low (bottom) motivational conditions. $\boldsymbol{B}, \boldsymbol{C}$, Cumulative $(\boldsymbol{B})$ and time-plot $(\boldsymbol{C})$ distributions of the discrimination onsets between acceptance and rejection by $\mathrm{ChV}$ units. The discrimination onsets were significantly earlier in the high motivational condition than in the low motivational condition in both cumulative (Kolmogorov-Smirnov test, ${ }^{* *} p<0.01$ ) and time-plot (Wilcoxon's rank-sum test, ${ }^{* *} p<0.01$ ) distributions. The median onset time in the high motivational condition was 222 ms earlier than that in the low motivational condition. $\boldsymbol{D}$, Temporal pattern of population activity of omission-type units around the cue onset (time 0 ) in omission error trials (red) and correct trials (blue). The numbers of dIPFC and ACC units are indicated, respectively, at the left and right of a plus sign. $\boldsymbol{E}$, Categorization of omission-type units. Many $(21$ of $36,58 \%)$ were not categorized by any of the five selected variables (Rew, Ave, ChV, RT, and FOE). None of them overlapped with motivation (FOE) units.

\section{Information encoded by $\mathrm{ChV}$ and FOE units was preserved in two tasks}

As shown in Figure 2, D and F, the ChV was clearly different for the Ap-Av and Ap-Ap tasks. If the ChV units represent exclusively the anticipatory value of chosen option irrespectively of the task conditions, the activity of $\mathrm{ChV}$ units should change across the two tasks. Conversely, as shown in Figure 1, E and $J$, the FOE was similar for the two tasks. If the FOE units represent exclusively motivational condition irrespectively of the task conditions, then they should not change their firing pattern between the two tasks. To examine this possibility, we compared the activity patterns of the recorded units in the Ap-Av task with the activity of the same units in the Ap-Ap task. First, we confirmed that the $\mathrm{ChV}$ units preserved the encoded information by changing their response to the visual cues depending on the task version. The $\mathrm{ChV}+$ units $(n=119)$ exhibited the highest firing rates for high reward and low cost in the Ap-Av task (Fig. 10A, left), and they showed increases in activity as either the red or yellow bar increased in length in the Ap-Ap task (Fig. 10A, middle). We calculated the correlation coefficients between the cue-period activity and the $\mathrm{ChV}$ for the Ap-Av (Fig. 2D) and Ap-Ap (Fig. 2F) tasks. The means of the distributions of the correlation coefficients were significantly positive in both the Ap-Av (one-sample $t$ test, $p<0.001)$ and Ap-Ap $(p<0.001)$ tasks (Fig. 10A, right). Similarly, for each ChV - unit $(n=75)$, we calculated the correlation coefficients between the cue-period activity (Fig. 10B, left and middle) and the $\mathrm{ChV}$ for the Ap-Av (Fig. 2D) and Ap-Ap
(Fig. $2 F$ ) tasks. The means of the correlation coefficients of the $\mathrm{ChV}-$ units were significantly negative in both the Ap-Av $(p<0.001)$ and Ap-Ap $(p<0.001)$ tasks (Fig. 10B, right), suggesting the preservation of $\mathrm{ChV}$ information for these units (Amemori and Graybiel, 2012).

Task performance with low motivation occurred at the low-low combined offers in both the Ap-Av and Ap-Ap task conditions (i.e., low reward and low airpuff in the Ap-Av task and low reward offers in the Ap-Ap task), and these were represented by the FOE (Fig. $1 E, J)$. We found that the FOE+ units $(n=120)$ also did not change their response to the cues between the two tasks (Fig. 10C, left and middle). We calculated the correlation coefficients between the cue-period activity and the FOE for the two tasks. The means of the correlation coefficients were significantly positive both in the Ap-Av $(p<0.001)$ and Ap-Ap $(p<0.001)$ tasks (Fig. $10 C$, right). Similarly for the activity of FOE - units ( $n=74$; Fig. $10 D$, left and middle), we calculated the correlation coefficients between the cue-period activity and the FOE for the two tasks. The means of the correlation were significantly negative in both Ap-Av $(p<0.001)$ and Ap-Ap $(p<0.05)$ tasks (Fig. 10D, right). These results suggested that the FOE units preserved the encoded information in both task versions.

Qualitatively, in the Ap-Ap task, both the $\mathrm{ChV}$ and motivation were minimal in the low-low condition, in which the reward offer was minimal (Figs. $1 J, 2 F)$. Thus, it was possible that the $\mathrm{ChV}$ and FOE units also exhibited similar activities in the Ap-Ap tasks. To assess quantitatively how the two task versions contributed to differentiate the activities of these units, we compared the $\mathrm{ChV}+$ and FOE - units and also the $\mathrm{ChV}-$ and $\mathrm{FOE}+$ units across the two tasks.

In the Ap-Av task, the activities of the $\mathrm{ChV}+$ units $(n=119$; Fig. 10A, left) were significantly different from those of the FOEunits ( $n=74$; Fig. $10 D$, left), especially when the size of the Ave was large and the size of the Rew was small (two-sample $t$ test, $p<$ 0.01; Fig. 11A). The two-dimensional correlation coefficient that quantified the similarity between $\mathrm{ChV}+$ and $\mathrm{FOE}-$ matrices was 0.57 . The firing rates of the $\mathrm{ChV}-$ units $(n=75$; Fig. $10 B$, left) were significantly different from those of the FOE + units $(n=120$; Fig. 10C, left), and the difference was especially large when the airpuff size was large and the reward size was small (two-sample $t$ test, $p<0.01$; Fig. 11B). The two-dimensional correlation coefficient between $\mathrm{ChV}$ - and $\mathrm{FOE}+$ matrices was 0.66.

By contrast, in the Ap-Ap task, $\mathrm{ChV}$ and motivation were similar, and the firing patterns of $\mathrm{ChV}$ units became similar to those of FOE units. These two types of unit fired in the low-low combined offers, in which the two reward offers associated with the different targets were both low. The mean firing rates of the $\mathrm{ChV}+$ units ( $n=119$; Fig. $10 \mathrm{~A}$, middle) were significantly different from those of the FOE - units ( $n=74$; Fig. $10 D$, middle) in the high reward condition (two-sample $t$ test, $0.01<p<0.05$; Fig. 11C), but the difference was smaller than that in the Ap-Av 
task (Fig. 11A). The two-dimensional correlation coefficient between the $\mathrm{ChV}+$ and $\mathrm{FOE}-$ matrices was 0.79 , indicating that the activities of these units were similar. The mean firing rates of the $\mathrm{ChV}-$ units ( $n=75$; Fig. $10 B$, middle) and those of the FOE + units $(n=120$; Fig. $10 C$, middle) were not significantly different for all combined offers (two-sampled $t$ test, $p>0.05$; Fig. $11 D)$. The twodimensional correlation coefficient between $\mathrm{ChV}-$ and $\mathrm{FOE}+$ matrices was 0.85, also indicating similar activities. These results suggest that the FOE and $\mathrm{ChV}$ units exhibited similar responses to the combined offers in the Ap-Ap task.

\section{Discussion}

Affective judgments about whether to accept or to reject an offer are determined by likes and dislikes, and these affective evaluations simultaneously trigger motivational responses that govern dynamic aspects of the decision-making processes. Because of this complex relationship between affective judgment and motivation, only a few studies dissociated these two neuronal processes in macaque monkeys (Roesch and Olson, 2004). By introducing an aversive stimulus as a component of the combined offer, we attempted to dissociate neuronal activity related to affective judgment from neuronal activity related to the motivation to perform the decision-making task. In the Ap-Av task, the ChV could be increased by cues indicating increasing reward but could be decreased by simultaneously delivered cues indicating increasing punishment. By contrast, the level of motivation to perform the task could be decreased by cues indicating decreases in both reward and punishment, inducing delay and occasional deferment in performance. We analyzed the activity exhibited by populations of dlPFC and ACC neurons during the decision period of the task and classified the recorded units based on the response properties to the behavioral parameters in the Ap-Av task. We found a different emphasis in the dlPFC and ACC units for motivational regulation. Despite many similarities in their responses, the dlPFC population included a greater proportion of neurons with activity related to upcoming delayed reaction and low motivational condition than did the ACC. Furthermore, the responses of the motivation-type units in the dlPFC occurred significantly earlier than those in the ACC. These results suggest that these two regions could function cooperatively but with differential emphases in affective judgment and motivational drive.

\section{Dissociated groups of neurons related to motivation and affective judgments}

Our findings are allied with studies of human value evaluation. The valence of evaluation and arousal during positive and negative valu-
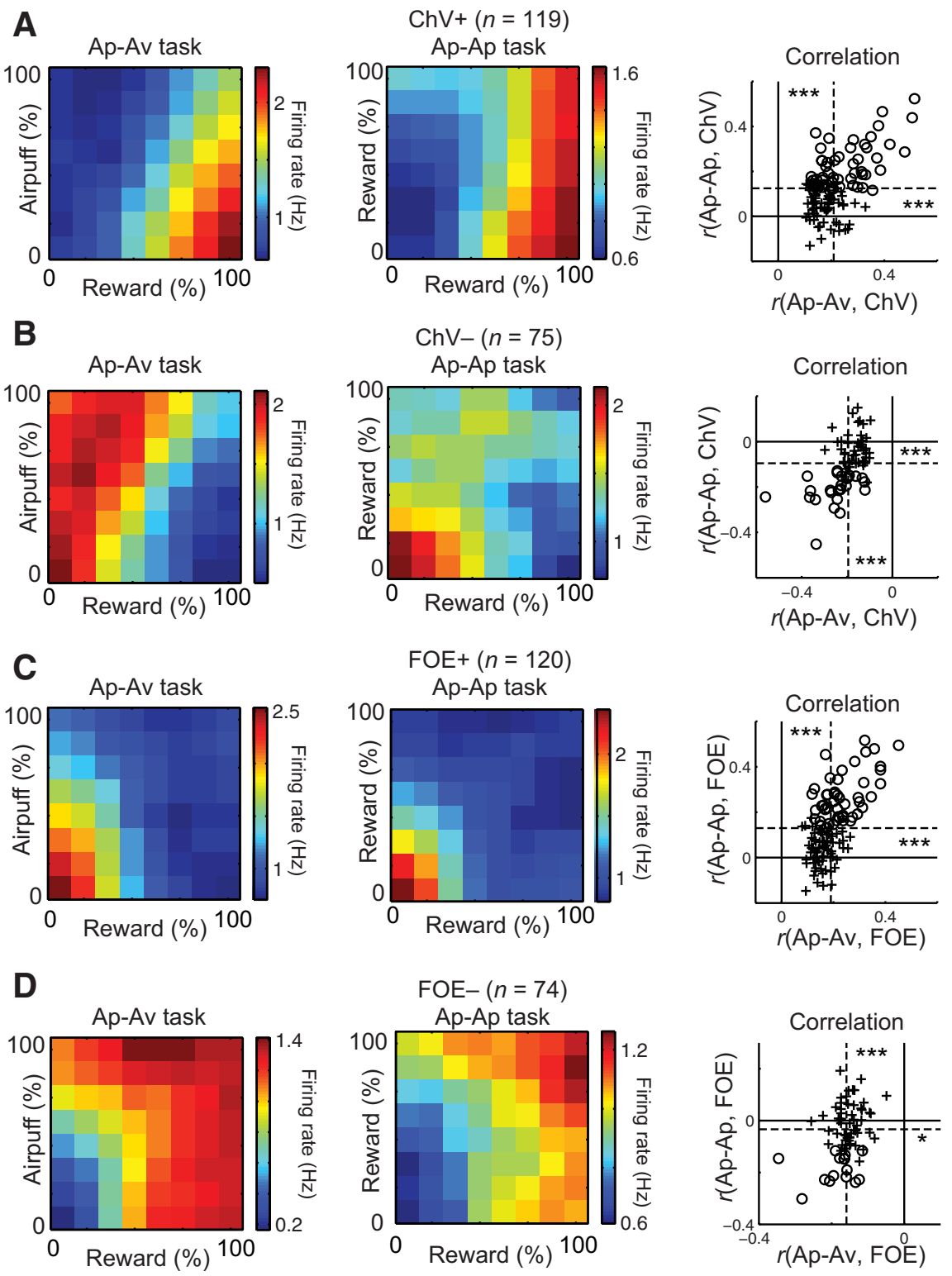

Figure 10. Encoded information was preserved across the $A p-A v$ and $A p-A p$ tasks. Population cue-period activity of ChV + $(\boldsymbol{A}), \mathrm{ChV}-(\boldsymbol{B}), \mathrm{FOE}+(\boldsymbol{C})$, and FOE - (D) units is plotted in relation to the combined cues in the Ap-Av (left) and Ap-Ap (middle) tasks according to the color scale at the right. Firing rates of each unit were baseline subtracted by the formula [Rate - min(Rate)] cue-period activity and the ChV, calculated for each neuron and for each task. Units with significant correlation (Pearson's correlation, $p<0.05$ ) in both tasks are marked by circles. Other units are marked by crosses. Dotted lines show mean correlation coefficients for each task. ${ }^{*} p<0.05,{ }^{* * *} p<0.001$ (one-sample $t$ test).

ation are considered to be dissociable, given that corresponding subjective preferences and physiological measurements of arousal are not always correlated positively (Lang et al., 1990; Bradley et al., 2001). For example, ratings of interest, viewing time, pupil size, respiration rate, and skin conductance can be increased by both pictures that are positively rated in terms of subjective preference and those that are negatively rated (Lang et al., 1998; Bradley et al., 2008; Keil et al., 2008), suggesting that states of arousal in the valuation process can be activated by stimuli of both positive and negative valence (Lang et al., 1990; Seymour et al., 2007; Codispoti et al., 2009; Lang and Bradley, 2010).

In electrophysiological studies in nonhuman primates, reward-related activity of neurons in the frontal cortex has been reported extensively (Watanabe, 1996; Kobayashi et al., 2002; 
A

$(\mathrm{ChV}+)-(\mathrm{FOE}-)$ in Ap-Av task

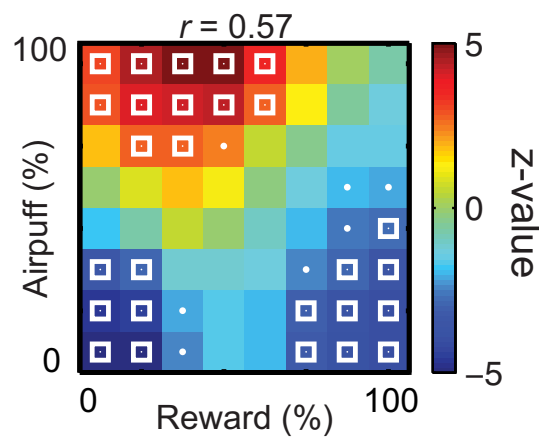

C

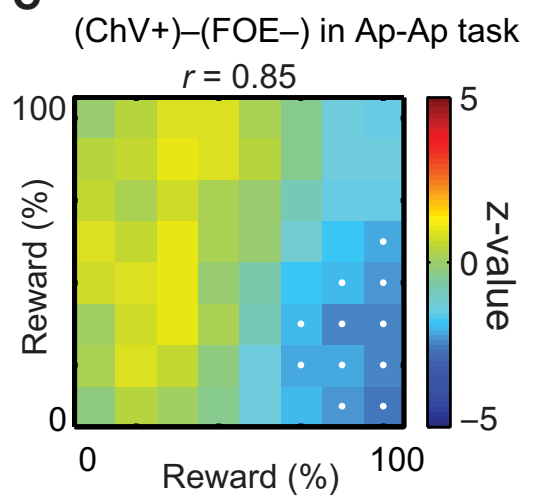

B

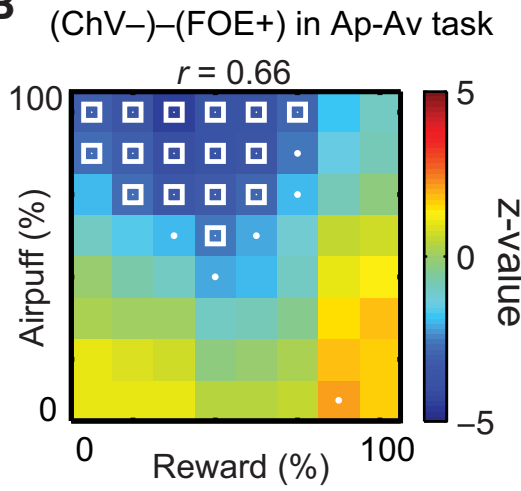

D

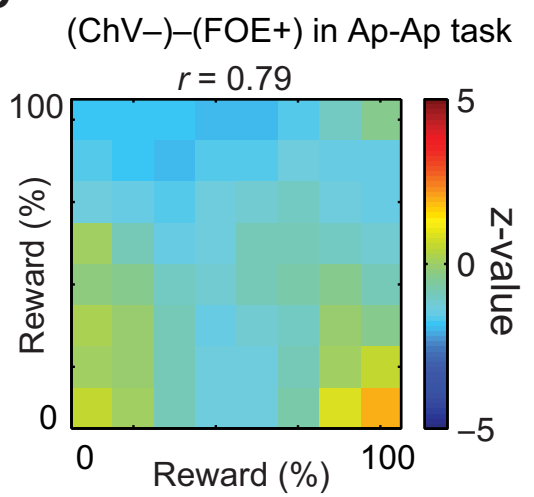

Figure 11. Motivation and ChV units are dissociable in the Ap-Av task. Differential activity between ChV + and FOE - units in the $A p-A v(\boldsymbol{A})$ and $A p-A p(\boldsymbol{C})$ tasks and between ChV - and FOE + units in the Ap-Av $(\boldsymbol{B})$ and $A p-A p(\boldsymbol{D})$ tasks, plotted as $z$ values (derived from two-sample $t$ test) for the combined cues. Combined cues that induced significant differences between the two populations are indicated by dots $(p<0.05)$ and squares $(p<0.01)$. The $r$ values indicate the two-dimensional correlation coefficients between the response patterns of $\mathrm{ChV}$ and $\mathrm{FOE}$ units, quantifying the similarity of two matrices. Firing rates of each unit were baseline subtracted by the formula [Rate - $\min ($ Rate)], where Rate indicates the firing rate of each element in the matrix.

Amemori and Sawaguchi, 2006; Kennerley and Wallis, 2009), and both the dlPFC and ACC have been implicated in valuebased decision-making (Lee et al., 2007; Rushworth et al., 2011; Hosokawa et al., 2013). Responses of frontal cortical neurons related to aversive stimuli have also been reported (Koyama et al., 1998; Kobayashi et al., 2006). However, few studies have addressed the question of whether these neurons can differentiate valence and motivational processes. An exception is the study by Roesch and Olson (2004), who recorded neuronal activity from the orbitofrontal cortex and premotor cortex as monkeys performed a task with different visual cues indicating the size of the reward for correct performance and the size of punishment for error performance. In contrast to the task that we used here, in the task used by these investigators, the monkeys could ignore the aversive cue and choose the reward-related cue by making a saccade. Orbitofrontal neurons responded preferentially to the valence parameter (offered reward size), whereas premotor cortical neurons responded to motivational parameter (task performance and RT).

\section{Task performance in low motivational conditions was dissociable from task disengagement}

Motivation affects the dynamics of decision-making processes (Tversky and Shafir, 1992; Watanabe, 1998; Diederich, 2003) and the percentage of correct task performance (Hassani et al., 2001; Shidara and Richmond, 2002). These behavioral findings raised the possibility that the dynamic aspect of neuronal processing related to decision-making was modulated by the different motivational conditions. Accordingly, we examined the neuronal onset of decision-making represented by the $\mathrm{ChV}$ units, units that were sensitive to the anticipated value of the eventually chosen outcome. We found that the discrimination onsets were, as expected, delayed in the low motivational conditions in which the FOE units were activated. However, the FOE units that exhibited differential activity in relation to motivational conditions did not overlap with neurons with activity that predicted omission errors. Thus, it is unlikely that the activity of FOE units is simply attributable to the error-related disengagement.

In a series of previous studies, the interaction between the dlPFC and ACC in primates has been examined in terms of attentional modulation (Rothé et al., 2011). The dlPFC response was shown to capture early-onset attentional selectivity (Kaping et al., 2011), whereas the ACC has been suggested to be particularly relevant to detecting errors indicating failures of inhibitory control of the attentional focus (Shen et al., 2014). In parallel with the error-related signals reported in the ACC, we found that a large proportion of the dlPFC units responded to the low motivational condition in which the monkeys patiently performed the task. These results suggest that motivational regulation for the low payoff condition could be different from the actual behavioral disengagement from task performance that we recorded here as omission errors.

\section{Differential emphasis of affective judgment and motivation among the responses of dIPFC and ACC units}

Roesch and Olson (2004), in studying macaques performing tasks requiring motor actions in relation to motivation, found sharp differences between the properties of units in the OFC and premotor cortex. Here, we observed many similarities between the response properties of units recorded in the dIPFC and ACC but also found that the ACC populations contained larger proportions of units encoding offered values (Rew and Ave units), and the dlPFC population contained larger proportions of units encoding motivation-related variables (RT and FOE units). We further found that the FOE units in the dIPFC population were activated earlier than those in the ACC, possibly to lead in time the motivational processing during the decision-making.

The primate dlPFC has long been implicated in cognitive control (Dias et al., 1996; Miller and Cohen, 2001; Koechlin et al., 2003), including suppression of impulsive (Iversen and Mishkin, 1970; Dias et al., 1997) and reflexive (Sasaki et al., 1989; Hasegawa et al., 2004; Kuwajima and Sawaguchi, 2007) responses. In another line of studies, behavioral inhibition has been recognized as a critical process induced by negative emotion (Gray, 1981, 1982; Carver and White, 1994), and the human dlPFC has been implicated in this process (Shackman et al., 2009). Our results suggest that many dlPFC units were activated when the monkeys per- 
formed the task in low payoff conditions and that this activity was not related to errors of omission. The FOE + units that had increased activity in the low payoff conditions could thus be related to the ability to perform patiently the task in the small reward conditions to gain large reward in later trials, a situation in which the dlPFC has been implicated by previous work (McClure et al., 2004; Tsujimoto and Sawaguchi, 2005; Figner et al., 2010).

\section{Concurrent neuronal processing of affective judgment and motivation}

We found that the information encoded by the neurons related to affective judgment and motivation could be preserved across the $A p-A v$ and Ap-Ap tasks. In principle, reward incentives enhance both the motivation to perform the task and the utility of acceptance, whereas the threat of potential punishment enhances the motivation to avoid but reduces the utility of acceptance. With the Ap-Av task, we were able to dissociate neurons encoding utility from those encoding motivation here defined as the correlate of the FOE. We found that the level of motivation in goaldirected behavior, at least in part, is processed by neuronal populations that are dissociable from populations dealing with affective judgment of the goal value. However, in the Ap-Ap task, the same neuronal populations were indistinguishable from one another, because the utility of acceptance was positively correlated with the approach motivation when the behavioral goal consisted of only rewards.

The two dissociable processes observed in the Ap-Av task, affective judgment and motivation, were concurrently activated during decision-making, raising the possibility that goal-directed behavior is organized by parallel processing dealing with behavioral regulation and goal evaluation. Our findings suggest that both the dorsolateral prefrontal and the anterior cingulate regions of the neocortex are involved in the integration of cost and benefit to derive affective judgments, and that the dlPFC could lead in time the regulation of motivational levels to govern the dynamic aspects of goal-directed behavior. Thus, the ACC and dlPFC could function in a cooperative manner during decisionmaking, with different relative assignments within this cooperative processing.

\section{References}

Amemori K, Graybiel AM (2012) Localized microstimulation of primate pregenual cingulate cortex induces negative decision-making. Nat Neurosci 15:776-785. CrossRef Medline

Amemori K, Sawaguchi T (2006) Contrasting effects of reward expectation on sensory and motor memories in primate prefrontal neurons. Cereb Cortex 16:1002-1015. CrossRef Medline

Barraclough DJ, Conroy ML, Lee D (2004) Prefrontal cortex and decision making in a mixed-strategy game. Nat Neurosci 7:404-410. CrossRef Medline

Belsley DA, Kuh E, Welsch RE (1980) Regression diagnostics: Identifying influential data and sources of collinearity. New York: Wiley.

Bradley MM, Codispoti M, Cuthbert BN, Lang PJ (2001) Emotion and motivation I: Defensive and appetitive reactions in picture processing. Emotion 1:276-298. CrossRef Medline

Bradley MM, Miccoli L, Escrig MA, Lang PJ (2008) The pupil as a measure of emotional arousal and autonomic activation. Psychophysiology 45: 602-607. CrossRef Medline

Cai X, Padoa-Schioppa C (2012) Neuronal encoding of subjective value in dorsal and ventral anterior cingulate cortex. J Neurosci 32:3791-3808. CrossRef Medline

Carver CS, White TL (1994) Behavioral inhibition, behavioral activation, and affective responses to impending reward and punishment: the BIS/ BAS scales. J Pers Soc Psychol 67:319-333. CrossRef

Codispoti M, Mazzetti M, Bradley MM (2009) Unmasking emotion: Exposure duration and emotional engagement. Psychophysiology 46:731-738. CrossRef Medline
Dias R, Robbins TW, Roberts AC (1996) Dissociation in prefrontal cortex of affective and attentional shifts. Nature 380:69-72. CrossRef Medline

Dias R, Robbins TW, Roberts AC (1997) Dissociable forms of inhibitory control within prefrontal cortex with an analog of the Wisconsin card sort test: restriction to novel situations and independence from "on-line" processing. J Neurosci 17:9285-9297. Medline

Diederich A (2003) Decision making under conflict: Decision time as a measure of conflict strength. Psychon Bull Rev 10:167-176. CrossRef Medline

Feingold J, Desrochers TM, Fujii N, Harlan R, Tierney PL, Shimazu H, Amemori K, Graybiel AM (2012) A system for recording neural activity chronically and simultaneously from multiple cortical and subcortical regions in nonhuman primates. J Neurophysiol 107:1979-1995. CrossRef Medline

Figner B, Knoch D, Johnson EJ, Krosch AR, Lisanby SH, Fehr E, Weber EU (2010) Lateral prefrontal cortex and self-control in intertemporal choice. Nat Neurosci 13:538-539. CrossRef Medline

Gray JA (1981) A critique of Eysenck's theory of personality. In: A model for personality (Eysenck H, ed), pp 246-276. Berlin: Springer.

Gray JA (1982) The neuropsychology of anxiety: an enquiry into the functions of the septo-hippocampal system. Oxford, UK: Clarendon, Oxford UP.

Hasegawa RP, Peterson BW, Goldberg ME (2004) Prefrontal neurons coding suppression of specific saccades. Neuron 43:415-425. CrossRef Medline

Hassani OK, Cromwell HC, Schultz W (2001) Influence of expectation of different rewards on behavior-related neuronal activity in the striatum. J Neurophysiol 85:2477-2489. Medline

Hosokawa T, Kennerley SW, Sloan J, Wallis JD (2013) Single-neuron mechanisms underlying cost-benefit analysis in frontal cortex. J Neurosci 33: 17385-17397. CrossRef Medline

Isoda M, Hikosaka O (2008) A neural correlate of motivational conflict in the superior colliculus of the macaque. J Neurophysiol 100:1332-1342. CrossRef Medline

Iversen SD, Mishkin M (1970) Perseverative interference in monkeys following selective lesions of the inferior prefrontal convexity. Exp Brain Res 11:376-386. Medline

Kaping D, Vinck M, Hutchison RM, Everling S, Womelsdorf T (2011) Specific contributions of ventromedial, anterior cingulate, and lateral prefrontal cortex for attentional selection and stimulus valuation. PLoS Biol 9:e1001224. CrossRef Medline

Keil A, Smith JC, Wangelin BC, Sabatinelli D, Bradley MM, Lang PJ (2008) Electrocortical and electrodermal responses covary as a function of emotional arousal: a single-trial analysis. Psychophysiology 45:516-523. CrossRef Medline

Kennerley SW, Wallis JD (2009) Reward-dependent modulation of working memory in lateral prefrontal cortex. J Neurosci 29:3259-3270. CrossRef Medline

Kennerley SW, Walton ME, Behrens TEJ, Buckley MJ, Rushworth MFS (2006) Optimal decision making and the anterior cingulate cortex. Nat Neurosci 9:940-947. CrossRef Medline

Kennerley SW, Behrens TE, Wallis JD (2011) Double dissociation of value computations in orbitofrontal and anterior cingulate neurons. Nat Neurosci 14:1581-1589. CrossRef Medline

Knoch D, Gianotti LRR, Pascual-Leone A, Treyer V, Regard M, Hohmann M, Brugger P (2006) Disruption of right prefrontal cortex by lowfrequency repetitive transcranial magnetic stimulation induces risktaking behavior. J Neurosci 26:6469-6472. CrossRef Medline

Kobayashi S, Lauwereyns J, Koizumi M, Sakagami M, Hikosaka O (2002) Influence of reward expectation on visuospatial processing in macaque lateral prefrontal cortex. J Neurophysiol 87:1488-1498. Medline

Kobayashi S, Nomoto K, Watanabe M, Hikosaka O, Schultz W, Sakagami M (2006) Influences of rewarding and aversive outcomes on activity in macaque lateral prefrontal cortex. Neuron 51:861-870. CrossRef Medline

Koechlin E, Ody C, Kouneiher F (2003) The architecture of cognitive control in the human prefrontal cortex. Science 302:1181-1185. CrossRef Medline

Koyama T, Tanaka YZ, Mikami A (1998) Nociceptive neurons in the macaque anterior cingulate activate during anticipation of pain. Neuroreport 9:2663-2667. CrossRef Medline

Kuwajima M, Sawaguchi T (2007) Involvement of the lateral prefrontal cortex in conditional suppression of gaze shift. Neurosci Res 59:431-445. CrossRef Medline 
Lang PJ, Bradley MM (2010) Emotion and the motivational brain. Biol Psychol 84:437-450. CrossRef Medline

Lang PJ, Bradley MM, Cuthbert BN (1990) Emotion, attention, and the startle reflex. Psychol Rev 97:377-395. CrossRef Medline

Lang PJ, Bradley MM, Cuthbert BN (1998) Emotion, motivation, and anxiety: brain mechanisms and psychophysiology. Biol Psychiatry 44:12481263. CrossRef Medline

Lee D, Rushworth MF, Walton ME, Watanabe M, Sakagami M (2007) Functional specialization of the primate frontal cortex during decision making. J Neurosci 27:8170-8173. CrossRef Medline

Matsumoto K, Suzuki W, Tanaka K (2003) Neuronal correlates of goalbased motor selection in the prefrontal cortex. Science 301:229-232. CrossRef Medline

McClure SM, Laibson DI, Loewenstein G, Cohen JD (2004) Separate neural systems value immediate and delayed monetary rewards. Science 306: 503-507. CrossRef Medline

McFadden D (1974) Conditional logit analysis of qualitative choice behavior. In: Frontiers in econometrics (Zarembka P, ed), pp 105-142. New York: Academic.

Miller EK, Cohen JD (2001) An integrative theory of prefrontal cortex function. Annu Rev Neurosci 24:167-202. CrossRef Medline

Miller NE (1971) Experimental studies of conflict. In: Selected papers on conflict, displacement, learned drives and theory. Experimental studies of conflict. Chicago: Aldine-Atherton.

Padoa-Schioppa C (2011) Neurobiology of economic choice: a good-based model. Annu Rev Neurosci 34:333-359. CrossRef Medline

Padoa-Schioppa C, Assad JA (2006) Neurons in the orbitofrontal cortex encode economic value. Nature 441:223-226. CrossRef Medline

Roesch MR, Olson CR (2004) Neuronal activity related to reward value and motivation in primate frontal cortex. Science 304:307-310. CrossRef Medline

Rothé M, Quilodran R, Sallet J, Procyk E (2011) Coordination of high gamma activity in anterior cingulate and lateral prefrontal cortical areas during adaptation. J Neurosci 31:11110-11117. CrossRef Medline

Rousseeuw PJ (1987) Silhouettes: a graphical aid to the interpretation and validation of cluster analysis. J Comput Appl Math 20:53-65. CrossRef

Rushworth MF, Noonan MP, Boorman ED, Walton ME, Behrens TE (2011) Frontal cortex and reward-guided learning and decision-making. Neuron 70:1054-1069. CrossRef Medline

Sasaki K, Gemba H, Tsujimoto T (1989) Suppression of visually initiated hand movement by stimulation of the prefrontal cortex in the monkey. Brain Res 495:100-107. CrossRef Medline

Seo H, Lee D (2007) Temporal filtering of reward signals in the dorsal anterior cingulate cortex during a mixed-strategy game. J Neurosci 27:83668377. CrossRef Medline

Seymour B, Singer T, Dolan R (2007) The neurobiology of punishment. Nat Rev Neurosci 8:300-311. CrossRef Medline

Shackman AJ, McMenamin BW, Maxwell JS, Greischar LL, Davidson RJ (2009) Right dorsolateral prefrontal cortical activity and behavioral inhibition. Psychol Sci 20:1500-1506. CrossRef Medline

Shen C, Ardid S, Kaping D, Westendorff S, Everling S, Womelsdorf T (2014) Anterior cingulate cortex cells identify process-specific errors of attentional control prior to transient prefrontal-cingulate inhibition. Cereb Cortex. Advance online publication. Retrieved December 15, 2014. doi: 10.1093/cercor/bhu028. CrossRef Medline

Shidara M, Richmond BJ (2002) Anterior cingulate: Single neuronal signals related to degree of reward expectancy. Science 296:1709-1711. CrossRef Medline

Talmi D, Dayan P, Kiebel SJ, Frith CD, Dolan RJ (2009) How humans integrate the prospects of pain and reward during choice. J Neurosci 29: 14617-14626. CrossRef Medline

Train K (2003) Discrete choice methods with simulation. New York: Cambridge UP.

Tsujimoto S, Sawaguchi T (2005) Neuronal activity representing temporal prediction of reward in the primate prefrontal cortex. J Neurophysiol 93:3687-3692. CrossRef Medline

Tversky A, Shafir E (1992) Choice under conflict: the dynamics of deferred decision. Psychol Sci 3:358-361. CrossRef

Vogel JR, Beer B, Clody DE (1971) A simple and reliable conflict procedure for testing anti-anxiety agents. Psychopharmacology 21:1-7. CrossRef Medline

Von Neumann J, Morgenstern O (1947) Theory of games and economic behavior. Princeton: Princeton UP.

Watanabe M (1996) Reward expectancy in primate prefrontal neurons. Nature 382:629-632. CrossRef Medline

Watanabe M (1998) Cognitive and motivational operations in primate prefrontal neurons. Rev Neurosci 9:225-241. Medline

Watanabe M, Cromwell HC, Tremblay L, Hollerman JR, Hikosaka K, Schultz W (2001) Behavioral reactions reflecting differential reward expectations in monkeys. Exp Brain Res 140:511-518. CrossRef Medline 